\title{
Deep Eutectic Solvents for Innovative Pharmaceutical Formulations.
}

Canh-Hung Nguyen ${ }^{1,2}$, Luc Augis ${ }^{1}$, Sophie Fourmentin ${ }^{3}$, Gillian Barratt ${ }^{1{ }^{*}}$ and FrançoisXavier Legrand ${ }^{1, *}$

${ }^{1}$ Université Paris-Saclay, CNRS UMR 8612, Institut Galien Paris-Sud, 5 rue Jean-Baptiste Clément, 92290 Châtenay-Malabry, France. e-mail addresses: hungdkh1010@gmail.com (Canh-Hung Nguyen), luc.augis@universite-paris-saclay.fr (L. Augis), gillian.barratt@universite-paris-saclay.fr (G. Barratt), francois-xavier.legrand@universiteparis-saclay.fr (F.-X. Legrand).

${ }^{2}$ Department of Pharmaceutics, Hanoi University of Pharmacy, 13-15 Le Thanh Tong Street, Hoan Kiem District, Hanoi, Vietnam. e-mail address: hungdkh1010@gmail.com (Canh-Hung Nguyen).

${ }^{3}$ Unité de Chimie Environnementale et Interactions sur le Vivant, SFR Condorcet FR CNRS 3417, Université du Littoral-Côte d'Opale, 145 Avenue Maurice Schumann, 59140 Dunkerque, France. e-mail address: lamotte@univ-littoral.fr (S. Fourmentin).

* Corresponding authors at: Université Paris-Saclay, CNRS UMR 8612, Institut Galien ParisSud, 5 rue Jean-Baptiste Clément, 92290 Châtenay-Malabry, France. e-mail addresses: gillian.barratt@universite-paris-saclay.fr (G. Barratt), francois-xavier.legrand@universiteparis-saclay.fr (F.-X. Legrand)

\section{Abstract}

Finding alternative solvents for industrial processes, such as chemical synthesis or extraction of biologically active molecules that are less toxic and more environmentally friendly than the organic solvents used up to now, is a major societal issue. These alternative solvents are often described as "green, biodegradable" solvents. Deep eutectic solvents, which are mixtures of simple and often naturally occurring compounds, have been extensively studied in this regard. Among their possible applications, there has been increasing interest in their use for the preparation of pharmaceutical formulations. Indeed, by changing the nature and ratio of their components, deep eutectic solvents can be adapted to a wide range of active molecules, from poorly soluble small molecules to labile macromolecules. The use of deep eutectic solvents to solubilize active molecules with low aqueous solubility and/or low permeability could be an alternative approach to increase their dissolution and in-vivo absorption. This could result in significant increases of bioavailability or enhanced therapeutic efficacy of currently marketed 
drugs. Moreover, deep eutectic solvents can be used to limit phenomena like polymorphism or degradation which present a challenge to drug formulation. However, despite being generally described as biodegradable and nontoxic due to the nature of their constituents, the safety of deep eutectic solvents, which possess both novel physico-chemical and biological properties, cannot be taken for granted and must therefore be carefully studied during development stages. Therefore, this chapter presents not only recent progress in the application of deep eutectic solvents in the development of formulations for improving therapeutic efficacy by different routes of administration but also studies that have been undertaken to investigate the toxicity of deep eutectic solvents to both living organisms and the environment.

Keywords: solubility, macromolecules, antimicrobial, topical route, oral route, nasal route.

\section{Abreviations:}

A: Acetamide

AA: Acrylic acid

ACA: Aconitic acid

Arg: Arginine

$\beta$-ala: $\beta$-Alanine

B: Betaine

C: Choline

CA: Citric acid

CC: Choline chloride

$\mathrm{CH}$ : Cholinium hydroxide

DEEAC: $N, N$-diethylethanolammonium chloride

EG: Ethylene glycol

F: Fructose

G: Glucose

GA: Glycolic acid

GE: Geranate

GL: Glycerol

GLA: Glutamic acid

GLN: Glutamine

HBA: Hydrogen bond acceptor

HBD: Hydrogen bond donor 
LA: Lactic acid

LAU: Lauric acid

MA: Malic acid

MEA: Maleic acid

MOA: Malonic acid

OA: Oxalic acid

P: Proline

PD: 1,2-Propanediol (Propylene Glycol)

PHE: Phenyalanine

S: Sucrose

TA: Tartaric acid

TEAC: Tetraethylammonium chloride

TEG: Triethylene glycol

TBAB: Tetrabutylammonium bromide

TPAB: Tetrapropylammonium bromide

U: Urea

W: Water

X: Xylitol

ZC: Zinc chloride

\section{Content:}

1. Introduction

1.1. Definitions and Components.

1.2. Physico-chemical properties - Characterization of deep eutectic solvents.

2. Toxicity of deep eutectic solvents.

2.1. Toxicity towards microorganisms.

2.2. Toxicity towards human cells lines and ex-vivo studies on skin.

2.3. Toxicity towards plants, invertebrates and fish.

2.4. In-vivo toxicity in rodents.

2.5. Attempts to predict toxicity of deep eutectic solvents.

3. Pharmaceutical applications of deep eutectic solvents.

3.1. Solubilisation of small molecules in deep eutectic solvents.

3.1.1. Early work and model drugs.

3.1.2. Anti-inflammatory and analgesic drugs. 
3.1.3. Phenols and flavonoids.

3.1.4. Photosensitisers.

3.1.5. Anti-microbial drugs.

3.1.6. Therapeutic deep eutectic solvents.

3.2. Solubilisation and stabilisation of high-molecular-weight molecules.

3.2.1. Cage Molecules.

3.2.2. Nucleic Acids.

3.2.3. Proteins.

3.3. Antimicrobial applications.

3.3.1. Deep eutectic solvents with intrinsic antimicrobial activity.

3.3.2. Therapeutic deep eutectic solvents for applications in the oral cavity.

3.3.3. Formulation of conventional antibiotics in deep eutectic solvents.

3.3.4. Formulation of photosensitizers in deep eutectic solvents for antimicrobial activity.

3.3.5. Molecular imprinting.

\subsection{Cutaneous applications.}

3.5. Oral applications.

3.6. Nasal applications.

3.7. Applications in formulation for drug delivery and biotechnology.

4. Conclusions.

Acknowledgments.

References.

\section{Introduction.}

Recent progress in synthetic organic chemistry, molecular modelling and high-throughput screening has led to the production of a large number of new chemical entities with specific pharmacological activity, as well as discovering new indications for existing molecules. However, for a promising molecule to become an effective medicine, it is necessary to select an adequate solvent for its formulation that will both preserve its integrity and be compatible with the requirements for administration to human patients. Many molecules that are revealed to have high specificity for pharmacological targets have low water solubility that limits both their formulation and their bioavailability; however traditional organic solvents are not acceptable for pharmaceutical applications and also present considerable constraints for manufacturing. At the same time, alternative routes of administration avoiding intravenous 
injection, such as oral and topical routes, are attracting more and more interest because of their ease of use and better acceptability. This brings new challenges to formulation and a need for suitable additives.

Ionic liquids (IL) and deep eutectic solvents (DES) have been studied for over a century, but interest in their pharmaceutical applications is more recent (Agatemor et al., 2018; Adawiyah et al., 2016). Both solvents are mixtures of low molecular weight organic salts, containing a hydrogen bond donor (HBD) and a hydrogen bond acceptor (HBA), that are liquid below $100^{\circ} \mathrm{C}$. In 2011, Choi et al. put forward the concept of natural deep eutectic solvents (NADES) composed of amino acids, sugars, sugar alcohols and polyalcohols that are found in living cells (Choi et al., 2011). They postulated that these compounds could represent a "missing link" between aqueous and lipophilic media and provide an environment that would allow cells to survive in extreme conditions such as dehydration. These compositions can be considered as "green solvents" that do not carry the same risks of toxicity and handling as traditional organic solvents (Durand et al., 2016; Vanda et al., 2018). As such, they have numerous applications in pharmaceutical formulations, which will be detailed in this chapter.

\subsection{Definitions and components.}

The terms "ionic liquid" and "deep eutectic solvent" are often used interchangeably, but there are differences between the two systems (see correspondence arising from Banerjee et al., 2018a; Rogers and Gurau, 2018 and from Banerjee et al., 2018b). Although both can be considered as low transition temperature mixtures, there are differences in the way in which they are obtained (Durand et al., 2016). Deep eutectic solvents are prepared by mixing two molecules and the driving force for their formation is hydrogen bonding. On the other hand, ionic liquids are organic or inorganic salts whose behaviour is mainly defined by ionic interactions. Within the category of deep eutectic solvents, some authors have proposed a subclass called natural deep eutectic solvents (NADES) composed of molecules that are found within cells, as mentioned above (Choi et al., 2011; Vanda et al., 2018). In this chapter we will concentrate on deep eutectic solvents, although ionic liquids will be included when they have been compared with deep eutectic solvents in the same experimental system.

As can be seen in Tables 1-6, by far the most frequently used hydrogen bond acceptor is choline or choline chloride, while the hydrogen bond donors are often organic acids or sugars, or urea. 


\subsection{Physico-chemical properties - Characterization of deep eutectic solvents.}

The physico-chemical characterization of deep eutectic solvents systems is based around thermal and rheological properties. The low transition temperature can be checked by simple measurement of melting point, but differential scanning calorimetry gives a more accurate picture of the thermal behaviour.

As far as rheology is concerned, viscosity can be an issue for deep eutectic solvents (Moura et al., 2017). On one hand, for topical applications, a more viscous preparation would be an advantage as long as it can be easily spread on the skin. On the other hand, for other routes, excessive viscosity would hamper administration by other routes, such as oral, and can be a cause of toxicity.

\section{Toxicity of deep eutectic solvents.}

For any new pharmaceutical ingredient, toxicity profiling is extremely important. Many of the studies described above included an assessment of the effect of the deep eutectic solvents on mammalian tissues. A few systematic studies of toxicity have been made. Since deep eutectic solvents are proposed as "green solvents", emphasis has often been placed on their toxicity to the environment and in particular aquatic organisms have often been used as indicators. The studies that have been published have usually focused on bacterial cells, human cell lines in culture and in-vivo studies in rodents, although other organisms such as fungal cells, plants, invertebrates and fish have also figured in the literature.

\subsection{Toxicity towards microorganisms.}

In 2013, Hayyan et al. first studied the toxicity of deep eutectic solvents towards bacterial and eukaryotic cells (Hayyan et al., 2013). They chose two Gram-negative bacteria species (Escherichia coli, Pseudomonas aeruginosa) and two Gram-positive ones (Bacillus subtilis, Staphylococcus aureus) as well as brine shrimp (Artemia saliva) larvae as an indicator of ecotoxicity. They used deep eutectic solvents prepared from choline chloride combined with urea, glycerol, ethylene glycol and triethylene glycol. In this study they observed no inhibition of bacterial growth. When Mao et al. investigated the toxicity of deep eutectic solvents composed of choline chloride and urea, ethylene glycol and glycerol towards Arthrobacter simplex, using growth, metabolic activity and membrane permeability as the criteria of toxicity, they observed that the toxicity of the deep eutectic solvents was lower than that of 
the individual components (Mao et al., 2018). The ability of the bacteria to perform biotransformations of steroids was also improved in the deep eutectic solvents.

Wen et al. attempted to assess deep eutectic solvent toxicity and biodegradability towards several organisms including a bacterium, Escherichia coli (Wen et al., 2015). The deep eutectic solvents were composed of choline chloride or choline acetate with urea, glycerol, acetamide or ethylene glycol at different molar ratios. Biodegradability was determined in closed bottles with microorganisms from a water treatment plant. In their experiments, studied solvents were toxic to bacteria at concentrations above $75 \mu \mathrm{M}$, and they inhibited bacterial growth much more than the individual components. As far as biodegradability was concerned, only the choline chloride:urea and choline chloride:acetamide deep eutectic solvents could be considered as fully biodegradable in their system (Wen et al., 2015).

In a study carried out by Radošević et al. (Radošević et al., 2018), the toxicity of natural deep eutectic solvents towards several strains of bacteria (Escherichia coli, Proteus mirabilis, Salmonella typhimurium, Pseudomonas aeruginosa, Staphylococcus aureus), as well as the fungal species Candida albicans was tested. They observed toxicity for compositions containing organic acids, but that the solvents possessed antioxidative activity.

More recently, Macário et al. approached the question of the ecotoxicology of deep eutectic solvents using mixture theory in an attempt to predict their toxicity as a function of their components (Macário et al., 2018a \& b). Toxicity was assessed using the inhibition of bioluminescence produced by the marine bacterium Aliivibrio fischeri. In one study, tetramethylammonium chloride, tetraethylammonium chloride and tetrapropylammonium chloride where used as hydrogen bond acceptors with ethylene glycol and 1-propanol as hydrogen bond donors. Mixture toxicity theory was used to analyse the results obtained with the deep eutectic solvents and with their components separately. Neither the individual components nor the solvents showed excessive toxicity. A model in which the hydrogen bond donor and hydrogen bond acceptor acted on different sites was found to give reasonable agreement with the data and allow the toxicity of deep eutectic solvents to be predicted. Among the hydrogen bond acceptor, toxicity increased with the length of the carbon chain: tetramethylammonium chloride being the least toxic and tetrapropylammonium chloride the most toxic (Macário et al., 2018a). In another study the same approach was applied to deep eutectic solvents based on choline chloride as hydrogen bond donor with a number of hydrogen bond acceptors including ethylene glycol and urea (Macário et al., 2018b). In this case, they observed an antagonistic effect between the components of the deep eutectic solvents, so that the mixture was less toxic than the sum of the parts. In particular, choline 
chloride with urea or 1-propanol gave products with very low toxicity, making them suitable for use as alternative "green" solvents.

Juneidi et al. used four fungal species (Phanerochaete chrysosporium, Aspergillus niger, Lentinus tigrinus and Candida cylindracea) as their reporter organisms (Juneidi et al., 2016). The deep eutectic solvents tested were based on choline chloride with alcohols, sugars, organic acids, urea and zinc chloride as the hydrogen bond donor component. Only zinc chloride and organic acids showed growth-inhibiting effects on fungi, which were reduced slightly when these components were in the form of a deep eutectic solvent rather than presented as individual compounds.

A recent review suggested that antimicrobial testing of deep eutectic solvents was better performed in liquid suspension culture than by antibiograms, so that toxicity could be monitored as a function of time (Torregrosa-Crespo et al., 2020). Using a novel deep eutectic solvent composition, acetylcholine chloride:acetamide 1:2, they observed toxicity to Escherichia coli at concentrations above $300 \mathrm{nM}$ and that this was partially due to acidification of the medium by degradation products of deep eutectic solvent components. This highlights the necessity of studying the stability of deep eutectic solvents over time as well as working with freshly prepared material.

\subsection{Toxicity towards human cells lines and ex-vivo studies on skin.}

The team of Hayyan has studied the toxicity of deep eutectic solvents based on choline chloride with four different hydrogen bond donors towards a panel of human cell lines, using a variety of criteria to assess toxicity (Hayyan et al., 2015). Again, the deep eutectic solvents studied were choline chloride with glycerol, ethylene glycol, triethylene glycol and urea, always in a 1:3 ratio. The cells lines were PC3 (prostate cancer), A375 (malignant melanoma), HepG2 (hepatocellular cancer), MCF-7 (breast cancer), H413 (oral carcinoma) and OKF6 (normal oral keratinocytes). The deep eutectic solvents, at different dilutions in culture medium, were compared with their individual components using the 3-(4,5-dimethylthiazol-2yl)-2,5-diphenyltetrazolium bromide (MTT) reduction assay. The results showed appreciable toxicity of the solvents, which was generally intermediate between that of the components, except for those based on urea, which were less toxic than the constituent chemicals. When the toxicity towards the cancer cell lines was compared with that towards the normal keratinocytes, only a small degree of selectivity towards malignant cells was observed.

Microscopic examination of MCF-7 cells after treatment with deep eutectic solvents at 100 $\mu \mathrm{M}$, approximately equal to the half maximal inhibitory concentration $\left(\mathrm{IC}_{50}\right)$, showed reduced 
confluence compared with control cells and some rounded cells characteristic of apoptosis (Figure 1). Therefore, flow cytometry was used to determine the proportion of annexinpositive cells, which was slightly increased with the deep eutectic solvents. On the other hand, no propidium iodide-positive (necrotic) cells were observed. Furthermore, no deoxyribonucleic acid (DNA) fragmentation was observed (Hayyan et al., 2015).
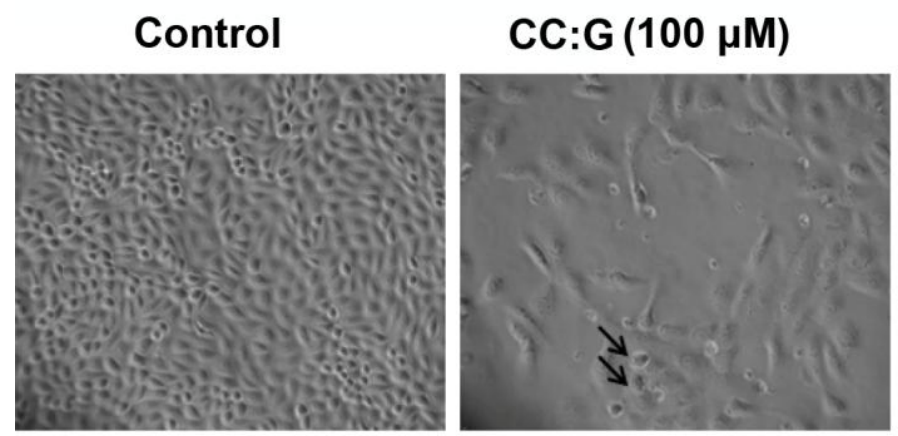

\section{CC:EG $(100 \mu \mathrm{M})$}
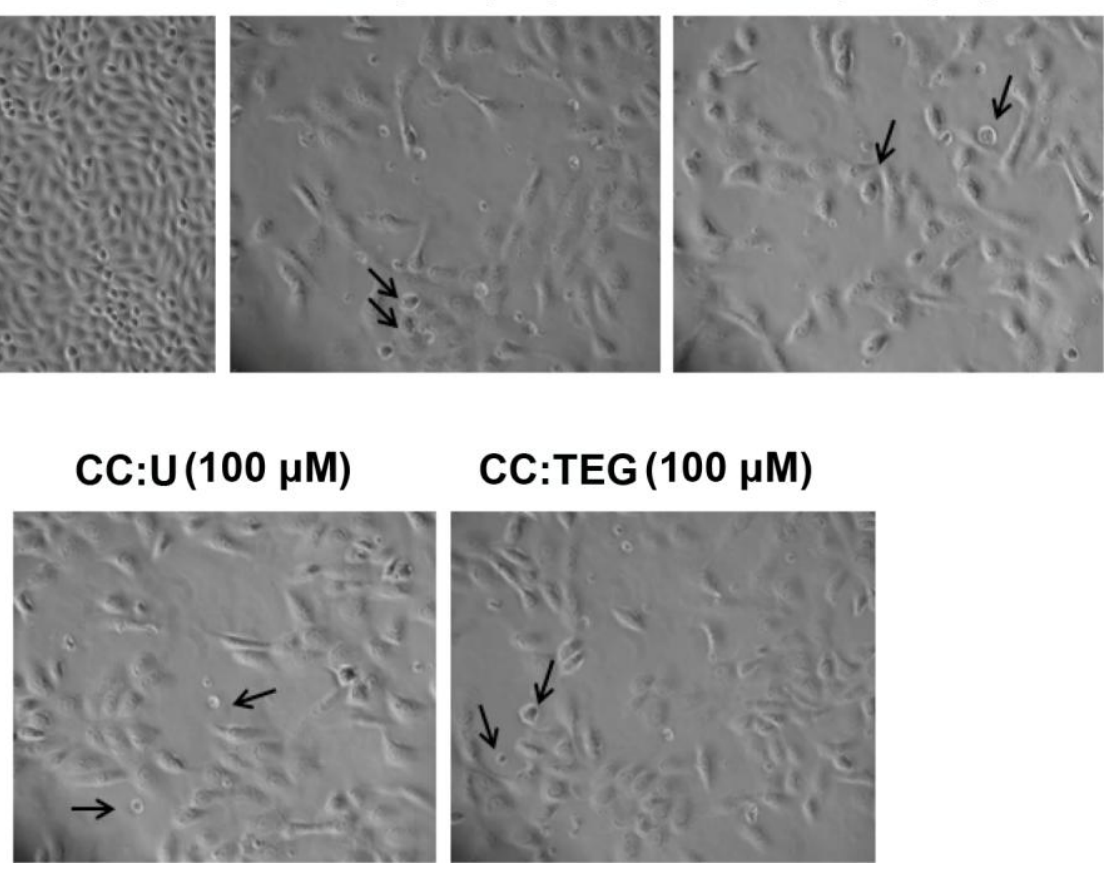

Figure 1. Morphological alterations of MCF-7 cells treated with deep eutectic solvents. Cells were treated with the half maximal inhibitory concentration of each solvent for $24 \mathrm{~h}$ and their morphology was analyzed using light microscopy. Arrow show shrunken or apoptotic cells (Hayyan et al., 2015).

Some evidence of membrane damage by deep eutectic solvents was provided by measuring the release of a cytoplasmic enzyme, lactic dehydrogenase, and the penetration of a fluorescent marker into the MCF-7 cells. The deep eutectic solvents containing ethylene glycol and triethylene glycol had more effect that the other two. The redox properties of the deep eutectic solvents were also studied. Firstly, the generation of reactive oxygen species (ROS) by MCF-7 cells was measured by a fluorogenic technique. The deep eutectic solvents caused a dose-dependent increase in reactive oxygen species production, which was particularly marked with choline chloride:triethylene glycol. Somewhat paradoxically, the authors also measured the antioxidant activity of the deep eutectic solvents, using quercetin as 
a positive control. Their radical scavenging capacity was found to be less than $1 \%$ of that of quercetin (Hayyan et al., 2015).

In a follow-up study, Hayyan et al. investigated the effect of introducing water into the deep eutectic solvents on the toxicity towards human cancer cell lines as described above (Hayyan et al., 2016). Deep eutectic solvents that contained choline chloride with fructose, glucose, sucrose or glycerol with water as a third component showed half maximal inhibitory concentration values above $100 \mathrm{mM}$, while a deep eutectic solvent composed of choline chloride and malonic acid alone, without water, was much more toxic. Since the viscosity of this solvent was not higher than some of the water-containing ones, and taking into account results from the literature, it was concluded that the presence of organic acids is a main source of deep eutectic solvent toxicity. They also used molecular modelling to investigate the possible interactions between deep eutectic solvents and membrane phospholipids. This predicted that deep eutectic solvents could interact with the cell surface.

Somewhat different in-vitro results were obtained by Radošević et al., who examined the cytotoxicity of deep eutectic solvents composed of choline chloride and five different hydrogen bond donors: glucose, fructose, xylose, glycerol and malic acid, towards two human cell lines: HeLa and MCF-7, using the 2-(4-iodophenyl)-3-(4-nitrophenyl)-5-(2,4disulfophenyl)-2H-tetrazolium (WST-1) reduction assay (Radošević et al., 2016). They found that the concentration that reduced 2-(4-iodophenyl)-3-(4-nitrophenyl)-5-(2,4-disulfophenyl)2H-tetrazolium (WST-1) metabolism by $50 \%$ was more than $2 \mathrm{mg} / \mathrm{mL}$ for all compositions. However, a deep eutectic solvent containing oxalic acid, although efficient for the application under consideration (extract of antioxidants from grape skin), was discarded because of slight toxicity (Radošević et al., 2015). In this study, in contrast to the results of Wen et al., (Wen et al., 2015) a high level of biodegradability was found for the tested solvents, with the lowest level being recorded for the solvent with oxalic acid. In a further study, a third human cell line, HEK293T, was added to the panel tested (Radošević et al., 2018). Only deep eutectic solvents containing organic acids (for example, citric acid) showed appreciable toxicity. These results were confirmed by Mitar et al. (Mitar et al., 2019), who also demonstrated the anti-oxidative properties of the natural deep eutectic solvents. In this work, a further criterion was added - corrosiveness towards metal (steel). This was found to be extremely low for all the deep eutectic solvents tested, meaning that they could be used in pipelines and reactors without any problem.

With a view to the oral administration of deep eutectic solvent-based formulations, Santos et al. tested the cytotoxicity of deep eutectic solvents based on citric acid against the intestinal 
cell line Caco-2 (Santos et al., 2019). Citric acid itself is quite toxic due to the acidic pH that it imparts to the culture medium while the two active molecules included (ethambutol and Larginine) were not toxic, with the deep eutectic solvents showing intermediate values.

Given the interest of deep eutectic solvents for topical applications, it is also important to determine whether irritation or any other toxicity is observed in the skin. An investigation was carried out in vitro by Santos de Almeida et al. on a human keratinocyte cell line, HaCat, using the 3-(4,5-dimethylthiazol-2-yl)-2,5-diphenyltetrazolium bromide (MTT) reduction assay (Santos de Almeida et al., 2017). They compared deep eutectic solvents based on choline combined with glutamine or phenylalanine with ionic liquids based on imidazoles. The choline-based solvents were found to be less cytotoxic than the imidazole-based ones. The results for the two choline-based solvents were very similar, with half maximal inhibitory concentrations for a $24-\mathrm{h}$ exposure of about $0.4 \% \mathrm{v} / \mathrm{v}$ in the culture medium.

Zakrewsky et al. chose a primary cell line - normal human bronchial epithelial cells to test the in-vitro toxicity of ionic liquids destined for transdermal delivery and combined this with the antimicrobial activity of the formulations to select the most promising for in-vivo applications (Zakrewsky et al., 2014). Of the 12 formulations tested, the "CAGE" formulation of choline and geranic acid and a choline-hexanoate formulation combined low cytotoxicity with high activity against biofilms. The potential for skin irritation was assessed by measuring interleukin- $\alpha 1$ secretion from a multilayer human skin model, and also by Fourier-transform infrared (FTIR) spectroscopy to look at changes in bands characteristic of skin lipids in porcine skin. Although its individual components caused significant interleukin- $\alpha 1$ release $4 \mathrm{~h}$ after application, the level observed with the choline:geranic acid solvent gave a result similar to the negative control. No changes in the band of the Fourier-transform infrared spectrum between $1650-1660 \mathrm{~cm}^{-1}$ were observed for the choline:geranic acid solvent and two other choline-based deep eutectic solvents, while the individual components caused significant changes. However, in their study of protein penetration through skin they observed stretching of the peaks between 2850 and $2920 \mathrm{~cm}^{-1}$ that are characteristic of lipid extraction (Banerjee et al., 2017). In a later study, the influence of the ratio of choline to geranic acid was investigated (Tanner et al., 2018). The decrease in the peak, indicating lipid loss, was proportional to the geranic acid content: that is, the hydrophobicity of the mixture. However, pure geranic acid did not promote insulin delivery through the skin, probably because it was too hydrophobic to dissolve the protein.

Macário et al. examined the potential skin toxicity of a number of deep eutectic solvents using two cells lines: HaCaT, a human keratinocyte line, and MNT-1, a human melanoma line, with 
3-(4,5-dimethylthiazol-2-yl)-2,5-diphenyltetrazolium bromide (MTT) reduction as the indicator of cell viability (Macário et al., 2019). In general, they observed that solvents containing choline chloride or tetramethylammonium chloride as hydrogen bond donor were not toxic to these cell lines, while those containing tetrabutylammonium chloride were toxic. As far as the hydrogen bond acceptors tested were concerned (butanoic acid, hexanoic acid, 1propanol, ethylene glycol and urea) only butanoic acid was toxic as an individual agent, while the deep eutectic solvents formed between this and tetramethylammonium chloride was only slightly toxic and choline chloride - butanoic acid was nontoxic.

Shekaari et al. measured the cytotoxicity of three deep eutectic solvents: choline chloride with ethylene glycol, glycerol or urea, against A549 lung cells using 3-(4,5-dimethylthiazol-2-yl)2,5-diphenyltetrazolium bromide (MTT) reduction as the criterion of toxicity and obtained half maximal inhibitory concentration values in the low millimolar range (Shekaari et al., 2019). Choline chloride-based deep eutectic solvents were evaluated for toxicity against HEK-293 human embryonic kidney cells by Ahmadi et al. (Ahmadi et al., 2018). The hydrogen bond donors were different sugars or alcohols. They observed that the solvents were more toxic than their starting components but that this toxicity was moderate, with half maximal inhibitory concentration values derived from 3-(4,5-dimethylthiazol-2-yl)-2,5diphenyltetrazolium bromide (MTT) reduction between 4 and 75 millimolar. The toxicity observed was lower than that of a classical imidazolium-based ionic liquid used in comparison. Of course, to obtain the half maximal inhibitory concentration values, the formulations must have been diluted to different extents in cell culture medium, so the interactions between the components of the deep eutectic solvents will have been altered.

Haraźna et al. recently proposed a new type of hydrogen bond donor: a mixture of $(R)-3$ hydroxyheptanoic and (R)-3-hydroxynonanoic acids derived from a bacterial cell wall polymer (Haraźna et al., 2019). These were used to form ionic liquids or deep eutectic solvents with a number of hydrogen bond acceptor, including choline chloride. Toxicity was assessed against the mouse embryonic fibroblast MEF 3T3 cell line, using a fluorescence microscopy technique to distinguish between live and dead cells. No reduction in cell viability was observed for concentrations up to $500 \mu \mathrm{g} / \mathrm{mL}$ of the choline chloride-based deep eutectic solvents. This deep eutectic solvent was also found to be completely biodegradable in 5 days in a standard test with activated sludge.

\subsection{Toxicity towards plants, invertebrates and fish.}


The study of Wen et al. included a plant (garlic, Allium sativum) and an invertebrate (hydra, Hydra sinensis) (Wen et al., 2015). Deep eutectic solvents containing choline chloride or choline acetate with urea, glycerol, acetamide or ethylene glycol in various proportions were tested. Some deep eutectic solvents or their components reduced root growth in garlic bulbs, in particular choline chloride and glycerol both had strong effects, but lower toxicity was observed when they were combined as a deep eutectic solvent. Similarly, the choline salts, particularly the chloride, were found to be detrimental to hydra growth, but the deep eutectic solvents were less toxic than the sum of their parts (Figure 2).

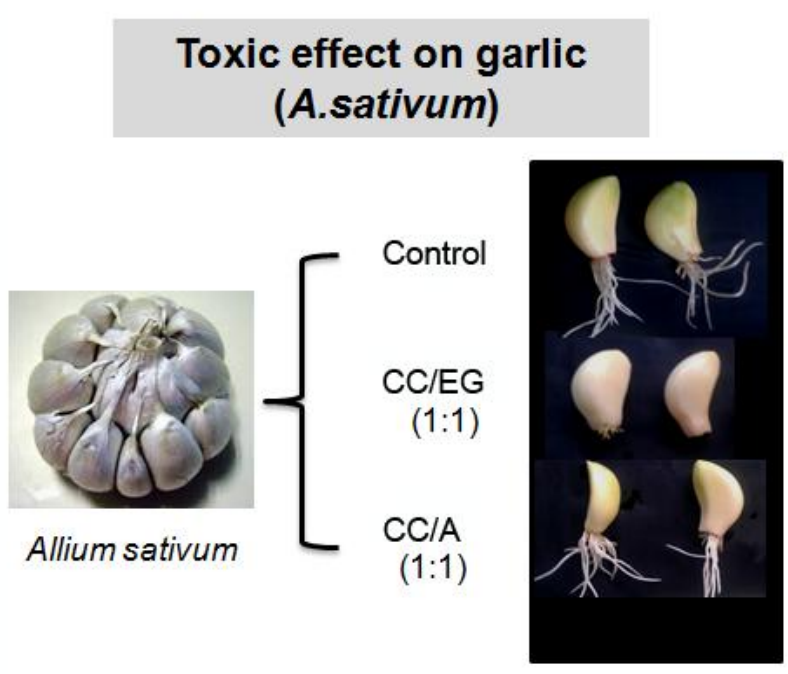

\section{Toxic effect on hydra \\ (H.sinensis)}

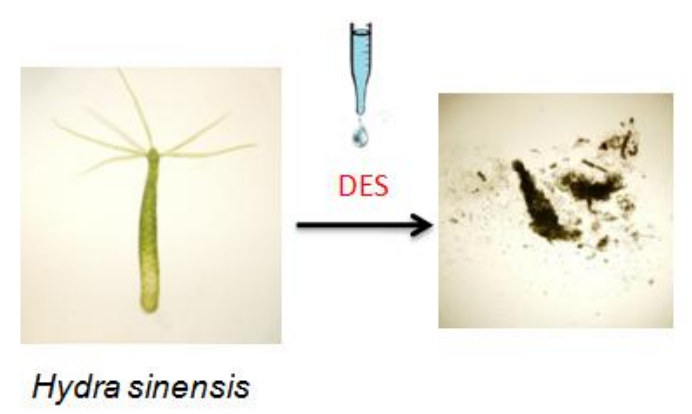

Figure 2. Effect of DES on garlic bulbs and on hydra (adapted from Wen et al., 2015 with permission of Elsevier).

Brine shrimp (Artemia saliva) larvae were chosen as an indicator of ecotoxicity by Hayyan et al. (Hayyan et al., 2013). Deep eutectic solvents prepared from choline chloride combined with urea, glycerol, ethylene glycol and triethylene glycol exerted some toxicity towards the shrimp larvae. This toxicity was more than the additive effect of the individual components, and the viscosity of the deep eutectic solvents was suggested as one possible explanation.

A more complex marine organism, the common carp (Cyprinus carpio) was used by Juneidi et al. to evaluate deep eutectic solvents based on choline chloride combined with alcohols, sugars, organic acids, urea and zinc chloride (Juneidi et al., 2016). Acute toxicity towards the fish was performed by adding the solvents to the water in the aquarium and adjusting the $\mathrm{pH}$ if necessary. Mortality was measured after 16 days. In agreement with their data obtained with fungi, only containing zinc chloride, malonic acid or para-toluenesulfonic acid showed median lethal dose values below $100 \mathrm{mg} / \mathrm{L}$. 


\subsection{In-vivo toxicity in rodents.}

Hayyan et al. determined the acute toxicity towards mice of a range of choline chloride based deep eutectic solvents. The median lethal dose $\left(\mathrm{LD}_{50}\right)$ of the deep eutectic solvents was determined in ICR mice after a single oral administration. Values of 5 to $6 \mathrm{~g} / \mathrm{kg}$ were obtained for the solvents with glycerol, ethylene glycol and triethylene glycol, while the choline chloride:urea 1:3 caused immediate death of the animals. However, a 1:2 composition had similar toxicity to the other solvents. Blood biochemistry showed some elevation of transaminases, indicative of liver damage. The conclusion of this study was that choline-based deep eutectic solvents are not completely devoid of toxicity and that the compositions need to be carefully considered (Hayyan et al., 2015). In a later study, some natural deep eutectic solvents were assessed using the same protocol (Mbous et al., 2017). However, the results of this in-vivo study are difficult to interpret because they are quoted in $\mathrm{g} / \mathrm{mL}$. The natural deep eutectic solvents were found to be less toxic than other deep eutectic solvents, despite the high viscosity of some natural deep eutectic solvents.

The safety of deep eutectic solvents for use in the extraction of phenolic compounds was considered by Benlebna et al., focussing on their possible effects after ingestion. They studied the toxicity of a green coffee bean extract in a deep eutectic solvents composed of betaine:glycerol (1:2 molar ratio) after repeated oral administration to rats (Benlebna et al., 2018). They encountered difficulties in administration due to the viscosity of the solvents and the deaths of two rats on days 5 and 10 after the first gavage. These rats were found to have a greatly enlarged stomach (Figure 3), which might have been related to the increased water consumption observed in the treated group. Increases in plasma and liver lipids were also recorded. Unfortunately, a control group with deep eutectic solvents without extract was not tested in this study. The results reinforce the conclusions of Hayyan et al. that deep eutectic solvents are not necessarily innocuous by the oral route (Hayyan et al., 2015). 


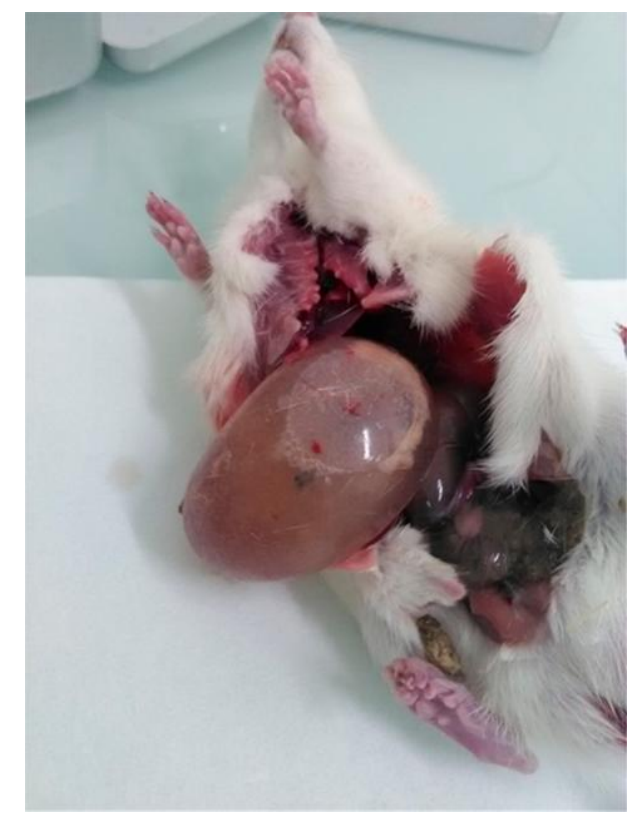

Figure 3. Photograph of the stomach of a rat that died five days after gavage with a glycerol:betaine NADES in a molar ratio 2:1 containing 10\% v/v of water (Benlebna et al., 2018, reprinted with permission of American Chemical Society)

On the other hand, Chen et al. tested the acute oral toxicity of a choline chloride:glycerol (1:2) solvent in rats and obtained a median lethal dose of 7,733 mg/kg (Chen et al., 2017). The mice that died did so within 4 hours of receiving the dose, and were first excited and then showed reduced activity, breathlessness, convulsions and tremor. In the studies of the oral bioavailability of insulin in the "CAGE" formulation of choline and geranic acid, no toxic effects and no histological changes in the intestines of the treated rats were observed (Banerjee et al., 2018a). When the ability of the "CAGE" formulation to reduce obesity, daily oral administration to rats for 30 days was well tolerated (Nurunnabi et al., 2019). Blood parameters and biomarkers of toxicity were unchanged compared with controls, and no abnormalities could be detected in the internal organs of the treated animals (Figure 4). 


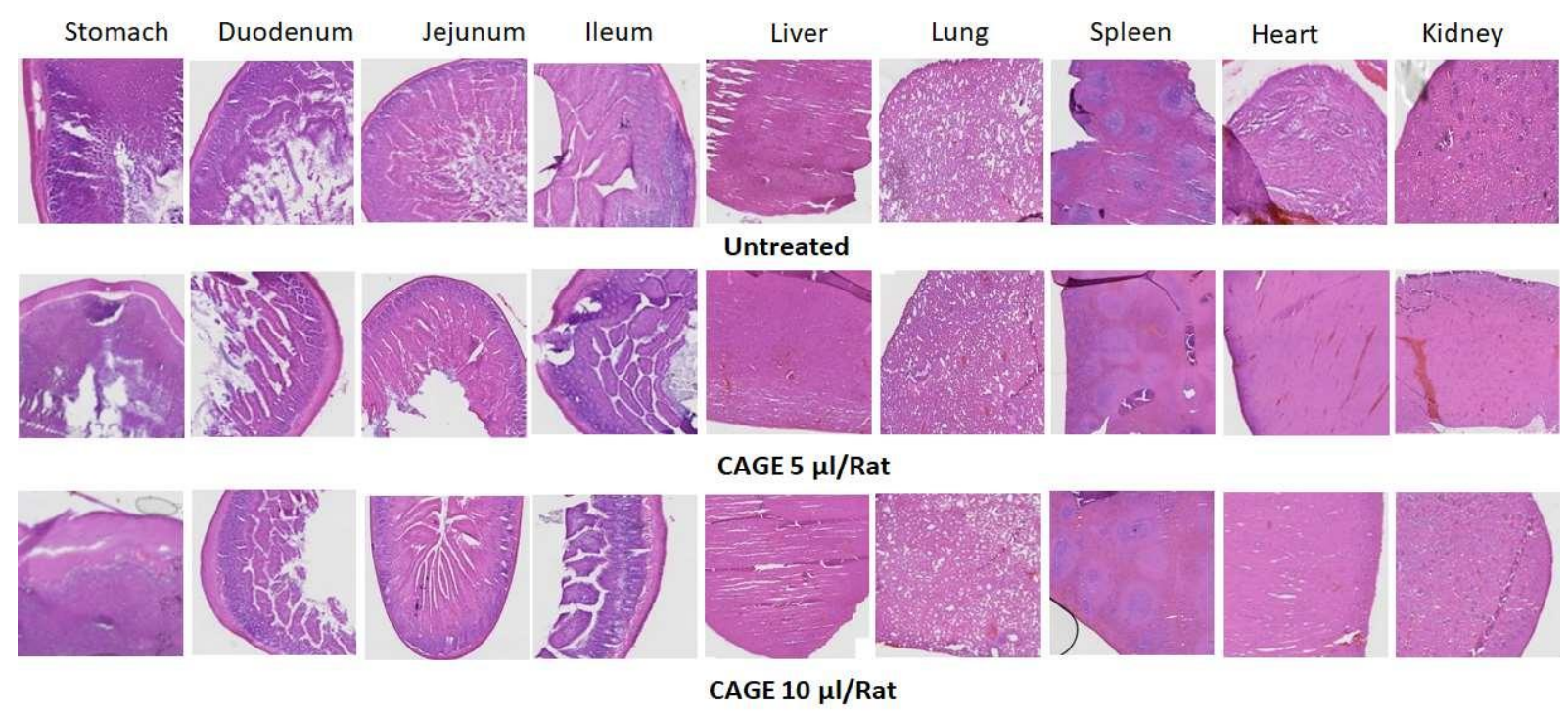

Figure 4. Photomicrographs of hematoxylin and eosin-stained harvested tissue sections after 30 days oral administration of CAGE (Nurunnabi et al., 2019; reprinted with permission of Proceedings of the National Academy of Sciences).

Faggian et al. did not mention any toxicity observed when they determined the oral pharmacokinetics of rutin administered to rats in a proline:glutamic acid 2:1 deep eutectic solvent (Faggian et al., 2016). Similarly, Sut et al. did not record any adverse events when measuring the oral pharmacokinetics of berberine in three different natural deep eutectic solvents (Sut et al., 2017).

\subsection{Attempts to predict toxicity of deep eutectic solvents.}

Table 1 summarizes the information above concerning the toxicity of deep eutectic solvents. It is clear that a wide range of different models and criteria of toxicity have been used, and that there is a need for more systematic investigations. Recently, a few investigators have tried to analyse the results to determine the parameters underlying toxicity and thereby predict it. Thus Macário et al. applied mixture theory to their results of toxicity towards a marine organism (Macário et al., 2018a \& b). Ahmadi et al. performed a Quantitative Structure Activity Relationships (QSAR) analysis on their data concerning the toxicity of choline chloride-based systems towards HEK-293 cells (Ahmadi et al., 2018). They were able to identify important structural parameters: the number of rotatable bonds, the mean atomic van de Waals volume and the $\mathrm{C} 2$ ratio of the hydrogen bond acceptor and hydrogen bond donor.

A recent article by Halder et al. has brought together data from a number of the studies reported above and subjected them to a multitasking-Quantitative Structure Toxicity 
Relationships (mtk-QSTR) analysis (Halder et al., 2019). This revealed a number of parameters that were important in determining toxicity: polarizability, electronegativity, nature of the hydrogen bond donor and topological features. They were able to rank the main classes of hydrogen bond donor in terms of deep eutectic solvent toxicity: sugar alcohols and straight-chain alcohols giving low toxicity, sugars and amides giving intermediate toxicity and organic and inorganic acids giving a high level of toxicity. More studies of this type, and more standardized protocols for toxicity studies, should in the future guide the choice of deep eutectic solvent compositions for pharmaceutical applications.

Table 1 summarizes the results that have been obtained to date about the toxicity of deep eutectic solvents. It is clear that a wide range of different models and criteria of toxicity have been used, and that there is a need for more systematic investigations.

\section{Pharmaceutical applications of deep eutectic solvents.}

It will be evident from the above that the main application of deep eutectic solvents in pharmaceutical science is as solvents for hydrophobic drugs. As well as a large number of small molecules, deep eutectic solvents have also been found to have advantages for solubilising larger macromolecules such as proteins, nucleic acids and polysaccharides. Not only do they increase solubility per se compared with aqueous media but may also increase the stability of the compound and favour particular conformations. Deep eutectic solvents have also been discovered to have intrinsic properties such as antimicrobial activity and as promoters of absorption.

\subsection{Solubilisation of small molecules in deep eutectic solvents.}

\subsubsection{Early work and model drugs.}

Some early work on deep eutectic solvents as vehicles for drug solubilisation was performed by Morrison et al. (Morrison et al., 2009). They studied the thermal properties of mixtures of choline chloride with urea or malonic acid using, among other techniques, hot stage microscopy, to allow them to define eutectic compositions of urea:choline chloride 2:1 and malonic acid:choline chloride 1:1. The solubility of five poorly water-soluble compounds (benzoic acid, danazol, griseofulvin, AMG517, itraconazole) in these mixtures was tested, yielding improvements in all cases; notably, an increase in the solubility of the antifungal drug itraconazole by 22,000 times compared with water. 
Dai et al. studied the potential of a range of natural deep eutectic solvent compositions as "green" solvents for a number of natural products with pharmaceutical activity: rutin, quercetin, cinnamic acid, carthamin, 1,8-dihydroxyl anthraquinone, taxol and ginkgolide B (Dai et al., 2013). A large array of combinations of compounds were screened using nuclear magnetic resonance (NMR) spectroscopy, thermogravimetric analysis, differential scanning calorimetry and viscosity measurements in order to characterise the mixtures. Four compositions were chosen for solubility studies: 1,2 propanediol:choline chloride:water 1:1:1, glucose:choline chloride:water 2:5:5, lactic acid:glucose:water 5:1:3 and xylitol:choline chloride:water 1:2:3. For all the active compounds cited, at least one of the natural deep eutectic solvents allowed a considerable increase in solubility compared with pure water, the most spectacular being that of quercetin multiplied over 400,000 times in xylitol:choline chloride:water. They also observed that temperature had a strong effect on solubility in natural deep eutectic solvents, with an increase of 1.6 to 2.3 times at $50^{\circ} \mathrm{C}$ compared with $40^{\circ} \mathrm{C}$. In a follow-up study, in 2015 , they investigated the effect of adding water to the natural deep eutectic solvents containing quercetin and carthamin, in an attempt to reduce the viscosity (Dai et al., 2015). Although the presence of water reduced hydrogen bonding in the deep eutectic solvents, a small proportion was able to reduce the viscosity significantly without much impact on the solubility of the active molecule.

Choi et al. reported that the solubility of the flavonoid rutin was 50-100 higher in natural deep eutectic solvents than in water, the highest solubility being attained in an aconitic acid:choline chloride mixture (Choi et al., 2011). They also reported good solubility of paclitaxel and ginkgolide B in a deep eutectic solvent composed of glucose and choline chloride. A naturally occurring alkaloid with antiparasitic activity, berberine, was formulated in deep eutectic solvents passed on proline and organic acids with the aim of improving its oral bioavailability (Sut et al., 2017).

In a study published in 2016, Li and Lee coined the term "deep eutectic solvent derivatives" for mixtures of choline chloride and carboxylic acids that, although not precisely eutectics, were liquid and room temperature ( $\mathrm{Li}$ and Lee, 2016). They determined the solubility of four model drugs (itraconazole, piroxicam, lidocaine, and posaconazole) in a choline chloride:glycolic acid 1:2 mixture. Again, the solubility of itraconazole and that of another antifungal from the same class, posaconazole, were greatly increased in these solvents, with smaller effects seen on piroxicam and lidocaine. The addition of a third component, oxalic acid, further increased the solubility of the antifungals, but also increased the viscosity of the formulations. 
Lidocaine (a local anaesthetic) was also used as a model compound for investigating the potential of deep eutectic solvents by Gutiérrez et al. (2018). In a first, theoretical, study, they examined the molecular interactions that could occur between lidocaine and the selected deep eutectic solvent components: choline chloride, $\beta$-alanine (hydrogen bond acceptors) and lactic acid (hydrogen bond donor) (Gutiérrez et al., 2018). In the second study, they studied deep eutectic solvents composed of arginine combined in an equimolar ratio with tartaric acid, oxalic acid and glutamic acid both theoretically and experimentally, using density functional theory and molecular dynamics (Gutiérrez et al., 2019).

Thioflavin $\mathrm{T}$ is a fluorescent molecule that undergoes a change when bound to amyloid fibrils and can therefore be used as a sensor for neurogenerative diseases. Gautam et al. studied the fluorescence behavior of this molecule in two deep eutectic solvents: choline chloride:urea 1:2 and $N, N$-diethylethanolammonium chloride:urea 1:2 (Gautam et al., 2018). High quantum yield and fluorescence lifetime were obtained in both solvents.

Palmelund et al. (2019). performed a similar study comparing experimentally determined solubility with theoretical predictions from conductor-like screening model for real solvents for a range of eleven active molecules in six deep eutectic solvents compositions and three conventional solvents (water, ethanol and polyethylene glycol 300 (PEG 300)). A good correlation was observed between the results, suggesting that predictive techniques could be used to reduce the number of experimental determinations. For most of the molecules tested, conventional solvents gave the best solubility, but often the best solvent was ethanol, which could bring toxicity and safety problems. However, for paracetamol and especially for celecoxib the highest solubility was obtained in a deep eutectic solvent.

\subsubsection{Anti-inflammatory and analgesic drugs.}

Non-steroidal anti-inflammatory drugs suffer from low water solubility. Lu et al. determined the solubility of five such drugs (aspirin, acetaminophen, ketoprofen, naproxen and ibuprofen) in a panel of deep eutectic solvents based on choline chloride, ethylammonium chloride, tetrapropylammonium bromide, betaine or choline bitartrate as the hydrogen bond acceptor and a variety of sugars, alcohols, organic acids and urea as the hydrogen bond donor (Lu et al., 2016). Good solubility was obtained in 17 selected deep eutectic solvents, but the authors were not able to predict solubility by looking at various physical properties of the deep eutectic solvents or at the hydrogen bond acceptor to hydrogen bond donor ratio. They also monitored the stability of aspirin in a choline chloride:1,2-propanediol (propylene glycol) 1:2 
solvents compared with pure water and a 1:1 solvent:water mixture and observed a reduced rate of cleavage to salicylic acid at $80^{\circ} \mathrm{C}$ in the deep eutectic solvent.

A later study by Mokhtarpour et al. focused on naproxen solubility in three deep eutectic solvent compositions: choline chloride:ethylene glycol 1:2, choline chloride:urea 1:2 and choline chloride:malonic acid 1:1 (Mokhtarpour et al., 2019a). All compositions increased the drug solubility more than 3300-fold with malonic acid as the hydrogen bond donor. They used several modelling procedures to attempt to predict solubility and performed density measurements to probe the interactions between the solvent and the solute. They also report a similar study with indomethacin in deep eutectic solvents composed of tetrabutylammonium bromide with ethylene glycol or glycerol (Mokharpour et al., 2019b). An increase of solubility of over 17,000-fold was obtained in the tetrabutylammonium bromide:ethylene glycol (TBAB:EG) solvent, compared with water.

Salicylic acid itself was one of two model compounds chosen by Santos de Almeida to investigate the feasibility of deep eutectic solvents for cutaneous applications, the other being caffeine (Santos de Almeida et al., 2017). They found that the best solubility was obtained with choline-based solvents, rather than those based on halogenated imidazole. As observed by Dai et al. for other drugs, solubility increased with increased temperature (Dai et al., 2013). Another salicylic acid derivative, salsalate, was formulated in a natural deep eutectic solvent composed of equimolar proportions of 1,2 propanediol, choline chloride and water, after testing a number of compositions. This provided a nontoxic alternative to dimethylsulfoxide (DMSO) for studies of its physiological effects in brown adipose tissue cells (Rozema et al., 2015).

The group of Shekaari have characterised the solubility of acetaminophen in choline-based deep eutectic solvents in close detail. In a first work, they compared urea, oxalic acid and malonic acid as hydrogen bond donors (Shekaari et al., 2017). The last named had the greatest impact on solubility. As might be expected, increasing concentrations of deep eutectic solvents in water and increased temperature increased the solubility. They measured the volumetric and compressibility properties in the drug in the different solvents to gain an insight into the interactions between the drug and the solvent, which were in fact found to be strong. In a follow-up study they added some thermodynamic measurements and determined that the main contribution to the energy of dissolution was enthalpic (Shekaari et al., 2018a). In another work, they performed similar experiments using deep eutectic solvents with the compositions choline chloride:glycerol 1:2 and choline chloride:ethylene glycol 1:2. Choline chloride:ethylene glycol was the better solvent (Shekaari et al., 2018b). They also extended 
their observations to another active molecule, the anti-epileptic drug lamotrigine, again finding that choline chloride/ethylene glycol was the best solvent of three tested (Shekaari et al., 2019).

\subsubsection{Phenols and flavonoids.}

Salvianolic acid B is a natural product with applications for cardiovascular diseases. Although it is water-soluble, it is easily hydrolysed with subsequent loss of activity. Chen et al. investigated the possible improvement in stability brought about by the use of deep eutectic solvents, composed of choline chloride with ethylene glycol, glycerol, 1,2 propanediol and 1, 4-butanediol (Chen et al., 2016). The degradation of salvianolic acid B was reduced in all tested solvents compared with water, with maximum stability observed in choline chloride:glycerol with an optimal molar ratio of 1:2. Infrared spectroscopy showed interactions between the deep eutectic solvents and the carbonyl group of this phenolic acid. The authors then determined the pharmacokinetics and acute toxicity of salvianolic acid B after oral administration within this optimised deep eutectic solvent (see below).

As well as their use as solvents for phenolic compounds, deep eutectic solvents have also been employed for the extraction of this type of molecule from plants. Thus, Benlebna et al. used a natural deep eutectic solvent composed of betaine and glycerol (1:2) to extract polyphenols from green coffee beans (Benlebna et al., 2018). However, some toxicity was observed when this extract was administered orally to rats (see section on toxicity above). Radošević et al. also used natural deep eutectic solvents to extract phenols and anthocyanins from grape skin (Radošević et al., 2016). Formulations combining choline chloride with glucose, fructose, xylose, glycerol and malic acid, in mixtures containing $30 \%$ of water were prepared. The best extraction efficiency was achieved with the deep eutectic solvent containing malic acid, judged not only by assay of the different molecules extracted, but also by the antioxidant capacity. The toxicity of the deep eutectic solvents determined in vitro towards two human tumour cell lines was low, while the antiproliferative activity of the choline chloride: malic acid extract was much higher than that of a traditional methanolic extract.

In a work designed to evaluate the antioxidant capacity of a number of phenolic compounds, Durand et al. used a natural deep eutectic solvent consisting of 1,2-propanediol (propylene glycol), choline chloride and water in equimolar proportions as a vehicle to add the active molecules to cultured fibroblasts (Durand et al., 2017). For compounds with low water solubility, this provided a better method for obtaining dose-response curves than ethanol or 
dimethylsulfoxide. The same group used this natural deep eutectic solvent to formulate resveratrol and test its ability to inhibit the enzyme matrix metalloprotease- 9 in cultures of activated macrophages, thereby avoiding the toxicity associated with dissolving the molecule in dimethylsulfoxide (Shamseddin et al., 2017).

Flavonoids are another class of antioxidant products for which deep eutectic solvents can bring considerable advantages in extraction and solubilisation. To this end, Tang et al. made a detailed study of the solubility of three plant-derived flavonoids: phloretin, phlorizin and naringin dihydrochalcone (naringin DC) in natural deep eutectic solvents that combined citric acid, choline chloride, glucose and sucrose in various combinations with water (Tang et al., 2016). The density and viscosity of the solvents were measured, and the solubility parameters were analysed. As observed in many studies, solubility in the natural deep eutectic solvents increased with increasing temperature. Taking all the factors into consideration, the best solvents for the extraction and solubilisation of flavonoids were reported to be citric acid:glucose:water 1:1:12 and choline chloride:citric acid:water 1:1:11.

The solubility of nobiletin, a glucose-lowering flavonoid, was enhanced 450 times compared with water in the so-called "CAGE" solvent consisting of geranic acid and choline in a 2:1 molar ratio. Nucleic magnetic resonance studies showed overlapping spectra, suggesting that the flavonoid might be able to act as a hydrogen bond acceptor within the solvent (Hattori et al. 2019).

\subsubsection{Photosensitisers.}

Photosensitising compounds have great potential for the treatment of both infections and cancer but are generally hydrophobic and thus difficult to administer. Photodynamic therapy (PDT) consists of first giving the photosensitizer which accumulates, with variable degrees of specificity, in the target (bacteria or tumour cell). On illumination, the photosensitiser produces reactive oxygen species that destroy the target. It is clear that the success of this therapy depends on fast and accurate accumulation of the photosensitiser in the target. A group at the University of Oslo has been studying the use of natural deep eutectic solvents as solvents for agent used in antimicrobial photodynamic therapy. They first evaluated a panel of solvents for a natural compound, curcumin (Wikene et al., 2015a). Of 17 solvents tested, 2 gave acceptable solubility; D-(+)-glucose:sucrose 1:1 and maleic acid:choline chloride 1:3. Hydrolysis of curcumin was also reduced in these solvents. The phototoxicity of these formulations towards bacteria is discussed in the section on the antimicrobial activity of deep eutectic solvents. They then turned their attention to an anionic porphyrin, meso-tetra-(4- 
carboxyphenyl)-porphine (TCPP) (Wikene et al., 2016). From absorption and fluorescence spectroscopy, meso-tetra-(4-carboxyphenyl)-porphine was found to be soluble in a dicationic form in acidic deep eutectic solvents formed from citric acid:sucrose 1:1; DL-malic acid:Dfructose:D-glucose 1:1:1 and choline chloride:xylitol 5:2. Phototoxicity was observed towards several bacterial species (see below).

The same group also investigated a neutral porphyrin, meso-tetra(4-hydroxyphenyl)porphine (THPP) (Wikene et al., 2015b). Two natural deep eutectic solvents were selected for their ability to increase the solubility and stability: citric acid:sucrose 1:1 and D-glucose:DL-malic acid 1:1. They were able to show increased phototoxicity towards Enterococcus faecalis and Escherichia coli compared with phosphate buffered saline. A follow-up study (Wikene et al., 2017) extended these observations to four bacterial and one fungal species. In 2016 a patent was filed entitled "Eutectic solvents and uses thereof" describing the use of deep eutectic solvents and natural deep eutectic solvents for bacterial killing by photodynamic therapy (Tønnesen and Wikene, 2016).

\subsubsection{Anti-microbial drugs.}

Other patent applications, filed by Zakrewsky et al., claim that a wide range of drugs can be incorporated into deep eutectic solvents to improve their transdermal penetration, with treatment of skin infections as a particular example (see below) (Zakrewsky et al., 2015; Zakrewsky et al., 2016b).

Several more specific reports have described the solubilisation of antimicrobial molecules in deep eutectic solvents. Olivares et al. have formulated two $\beta$-lactam antibiotics, clavulanic acid and imipenem in the composition of betaine and urea in a molar ratio of 1:1.5 (Olivares et al., 2018). They used spectroscopic techniques (infrared (IR) and nuclear magnetic resonance) to characterize the deep eutectic solvents, with the results highlighting the importance of hydrogen bonds in their microstructure and the disruption of this structure by addition of water. Both the chemical stability and the antimicrobial activity of the two antibiotics was increased several folds by incorporation into the solvents compared with an aqueous solution. The solubility of antofoxacin hydrochloride, an antibiotic in the fluoroquinolone family, was found to be increased in a deep eutectic solvent composed of choline chloride:para-toluenesulfonic acid 1:2 compared with ethanol:water and ethanol:acetonitrile mixtures (Zhang et al., 2019).

Two other antibacterial molecules - sulfanilamide and sulfacetamide, were solubilised in natural deep eutectic solvents based on choline chloride paired with glycerol, sugars or sugar 
alcohols (Jeliński et al., 2019). They reported both experimental results and theoretical determinations of thermodynamic parameters using the conductor-like screening model for real solvents (COSMO-RS) protocol. The solvent composed of choline chloride and glycerol in a 1:1 molar ratio gave the highest solubility, and in general equimolar proportions were the best solvents. In the theoretical model, these mixtures were found to have the lowest enthalpy.

\subsubsection{Therapeutic deep eutectic solvents.}

It is possible that an active molecule can itself act as a component of a deep eutectic solvent. As early as 1998, Stott et al. combined the non-steroidal anti-inflammatory drug ibuprofen with a number of terpenes, including menthol and thymol to form eutectic mixtures in an attempt to improve the transdermal penetration of the drug (Stott et al., 1998). In 2015, Su and Klibanov investigated the possibility of forming deep eutectic solvents with aspirin as the hydrogen bond donor (Su and Klibanov, 2015). They observed that in a mixture with choline chloride (choline chloride: aspirin 2:1) the solubility of aspirin was greatly increased, and it was also more resistant to degradation in the deep eutectic solvent. Tarate and Bansal described a deep eutectic solvent formed between coenzyme $Q$ and lauric acid in a 2:1 molar ratio (Tarate and Bansal, 2015). Abbott et al. also described the formation of deep eutectic solvents between choline chloride and active pharmaceutical ingredients that could act as hydrogen bond donors, such as salicylic acid, paracetamol and aspirin, or between hydrogen bond acceptors including adiphenine and ranitidine with glycerol, urea or aspirin (Abbott et al., 2017).

A similar approach was taken with erythritol, a sugar alcohol that is able to inhibit the growth of biofilms and dental plaque. Lim et al. mixed this with a zwitterion, betaine, and formed a complex that was stable in water and capable of dispersing biofilms (Lim et al., 2017). Although this may not be strictly considered as a deep eutectic solvent, they obtained similar results with a mixture of erythritol and zinc chloride (Lim et al., 2018). The cationic complex formed was found to disrupt the interactions within bacterial exopolysaccharides. In a similar vein, Wang et al. created an antibacterial deep eutectic solvent using the cationic antiseptic benzalkonium chloride with acrylic acid (Wang et al., 2017). The resulting mixture could be incorporated into a dental composite that showed good mechanical properties and biocompatibility.

In a study undertaken by Santos et al. in 2019, two molecules that could have activity in the treatment of tuberculosis, the antibiotic ethambutol and L-arginine, which can relieve the symptoms of tuberculosis by stimulating the immune system, were combined with citric 
(Santos et al., 2019). The systems were characterized by polarized optical microscopy, differential scanning calorimetry (DSC) and nuclear magnetic resonance. The solubility of ethambutol in the deep eutectic solvent was considerably higher than that in water. Some toxicity was observed towards Caco- 2 cells, which seemed to be linked to the acid $\mathrm{pH}$ of the solvents (Santos et al., 2019).

Aroso et al. were the first to refer to this sort of system as therapeutic deep eutectic solvents (THEDES). They performed a study in which they associated three drugs that can act as hydrogen bond donors (acetylsalicylic acid, benzoic acid and phenylacetic acid) with choline chloride or menthol (Aroso et al., 2016). The antibacterial activity of benzoic and phenylacetic acids was maintained in the solvents. They also showed increased permeability through an artificial membrane when the drugs were formulated in this way (Duarte et al., 2017).

Wolbert et al. attempted to use thermodynamic modeling to predict the formation of therapeutic deep eutectic solvents (Wolbert et al., 2019). Lidocaine, ibuprofen and phenylacetic acid were used as examples of drugs that could act as hydrogen bond donors, while the potential hydrogen bond acceptors were thymol, vanillin, lauric acid, para-toluic acid, benzoic acid and cinnamic acid. Predictions were made based on melting temperature and melting enthalpy and differential scanning calorimetry was used to confirm the formation of a deep eutectic solvent. In most cases, the melting point of the mixture could be predicted to $+/-3^{\circ} \mathrm{C}$. They were also able to model the behaviour of a ternary system of lidocaine, thymol and water. This revealed that a small amount of water did not necessarily perturb the formation of a therapeutic deep eutectic solvent. Other solvents formed from lidocaine and prilocaine and their hydrochloride salts were studied by Wojnarowska et al. both experimentally by differential scanning calorimetry and crystallography as well as in-silico methods. Both the ionic (hydrochloride) and the non-ionic combinations were able to form eutectic mixtures. The importance of hydrogen bonding in the non-ionic deep eutectic solvents was highlighted (Wojnarowska et al., 2018).

Pereira et al. investigated the formation of therapeutic deep eutectic solvents between a monoterpene with anticancer activity, limonene, and capric acid, malic acid, ibuprofen and menthol. In particular, the combination with ibuprofen increased the solubility of the antiinflammatory drug and reinforced its activity against reactive oxygen species, while also possessing antiproliferative activity against HT29 cells (Pereira et al., 2019).

After using their own observations and data from the literature on choline chloride-based deep eutectic solvents, Abranches et al. used the conductor-like screening model for real solvents 
method to generate a model and attempt to predict the formation of therapeutic deep eutectic solvents from acetylsalicylic acid, ibuprofen, paracetamol and ketoprofen (Abranches et al., 2019). In general, they found good agreement between the eutectic temperature calculated from the model and that observed experimentally. The results of all these studies using insilico techniques to predict eutectic formation should allow a more rational approach to formulation compared with the empirical one that has been used up to now.

All these observations concerning the solubility of pharmaceutically active low molecular weight compounds in deep eutectic solvents are summarized in Table 2.

\subsection{Solubilisation and stabilisation of high-molecular-weight molecules.}

As well as their applications for formulation of small molecules, deep eutectic solvents have also been found to be good solvents for biological macromolecules. As early as 2011, Choi et al. observed good solubility of salmon deoxyribonucleic acid (DNA), albumin, amylase and starch in some natural deep eutectic solvents (Choi et al., 2011).

In their 2013 study, Dai et al. included three high-molecular-weight natural products: gluten (a plant protein), deoxyribonucleic acid and starch (Dai et al., 2013). For each of these compounds, a deep eutectic solvent composition was found that could increase their solubility compared with water. For starch, which is not soluble in pure water even at $100^{\circ} \mathrm{C}, 7.55$ $\mathrm{g} / \mathrm{mole}$ solvent were detected in glucose:choline chloride:water 2:5:5 at this temperature. The solubilities of both gluten and deoxyribonucleic acid were both increased in a solvent consisting of lactic acid, glucose and water in a 5:1:3 molar ratio, by factors of 88 and 34 respectively. Recently, Haraźna et al. showed a good solubility of lignin, a biopolymer from wood, in a solvent formed from choline chloride and a mixture of bacterially derived organic acids (Haraźna et al., 2019).

Table 3 gives a summary of the applications of deep eutectic solvents to biomacromolecules. Some more detailed results for several classes of macromolecule are given below.

\subsubsection{Cage molecules.}

Cyclodextrins and curcurbit[n]urils are smaller macromolecules that have the particularity of being cyclic cage molecules that can complex a wide range of guest molecules. As such, they have a number of applications in the pharmaceutical and food industries, but their watersolubility can be limiting, especially for curcurbit $[n]$ urils and $\beta$ - and some substituted 
cyclodextrins. In 2016, a patent application filed by Fourmentin et al. (Fourmentin et al, 2016) it was reported that cyclodextrins could be dissolved in deep eutectic solvents composed of choline chloride and urea. In follow-up studies (Moufawad et al., 2019), the dissolution process of cyclodextrins in this deep eutectic solvent was described in detail and it was shown that the ability of the cyclodextrin to form inclusion complexes with methyl orange was retained. Furthermore, the effect of adding water to the system was studied, and a complex formed between $\beta$-cyclodextrin and piroxicam in the deep eutectic solvent was characterised by nuclear magnetic resonance (NMR) (Colombo Dugoni et al., 2019). More recently, El Achkar et al. have demonstrated the possibility of preparing a low melting mixture composed of levunilic acid and a cyclodextrin: the randomly methylated $\beta$-cyclodextrin that is able to include trans-anethole (Achkar et al., 2020).

Another patent (Scherman and McCune, 2018) concerns the use of deep eutectic solvents for the solubilisation of cage molecules including cyclodextrins and curcurbit $[n]$ urils. These authors used a deep eutectic solvent of choline chloride and urea in a 1:2 molar ratio to dissolve these compounds and found an increase in solubility compared with water for all classes that was as high as 55-fold for $\beta$-cyclodextrin (McCune et al., 2017). With the aid of a coloured reporter molecule, methylviologen, they were able to show that dissolution in the deep eutectic solvent did not upset the cage-guest equilibrium. These results with cage molecules open up many opportunities for pharmaceutical formulation.

\subsubsection{Nucleic acids.}

As a result of their specific base-pairing properties, nucleic acids have many applications in biomedical science, both in therapeutic and diagnostic scenarios. However, nucleic acid structures are not extremely stable in aqueous solution. Tateishi-Karimata and Sugimoto have reviewed work in which nucleic acids have been dissolved in a hydrated ionic liquid composed of choline dihydrogen phosphate and a deep eutectic solvent made of choline chloride and urea (Tateishi-Karimata and Sugimoto, 2014). They reported differences in basepairing compared with sodium chloride solution, and a stabilization of triplexes in ionic liquid and quadruplexes in deep eutectic solvent. Since these structures are used in a number of devices in nanomedicine, this is an important result. Gállego et al. studied the formation of deoxyribonucleic acid nanostructures in deep eutectic solvents using atomic force microscopy, mobility on agarose gels and circular dichroism (Gállego et al., 2015). They observed that a deep eutectic solvent composed of choline chloride and glycerol in a 1:4 ratio allowed folding into complex structures that could be transferred into aqueous solution. 


\subsubsection{Proteins.}

Ionic liquids and deep eutectic solvents are also attracting much interest as alternative solvents for proteins, for both fundamental studies and applications in medicine and biotechnology. The three-dimensional structure of protein molecules is essential for their function but is only marginally stable, being held together by a large number of weak interactions: hydrogen bonds, electrostatic interactions, van de Waals forces and hydrophobic interactions. It follows that the solvent has a profound influence on protein conformation and activity. Given that, as discussed by Choi et al. many components of deep eutectic solvents are found in living cells and may be involved in survival of stress conditions, they could be considered as a potential alternative to aqueous solvents for proteins (Choi et al., 2011). This hypothesis was investigated by Sanchez-Fernandez et al. with respect to two model proteins: lysozyme and bovine serum albumin (BSA) (Sanchez-Fernandez et al., 2017). Two main physiochemical techniques were used to probe the protein structure: circular dichroism and small-angle neutron scattering (SANS). In particular, circular dichroism in the far-ultraviolet (far-UV) region gives an indication of the secondary structure of the protein and allows the proportion of $\alpha$-helix, $\beta$-sheet and random coil to be estimated. On the other hand, the nearUV region gives information on the tertiary structure.

The solubility of bovine serum albumin, bovine pancreatic $\alpha$-chymotrypsinogen, bacteria subtilisin and hen egg-white lysozyme in a panel of low transition temperature mixtures was tested by $\mathrm{Su}$ and Klibanov ( $\mathrm{Su}$ and Klibanov, 2015). The solubilities depended on the composition of the mixture and the protein, but in some cases, solubility approaching that obtained in aqueous solution. The enzymatic activity of lysozyme was tested in a number of mixtures and found to be almost completely conserved. The thermal stability of the enzyme was also conserved, or even increased.

As indicated by circular dichroism, the secondary structure of bovine serum albumin was not affected by the use of a deep eutectic solvent composed of choline chloride and glycerol either pure or mixed with water, compared with phosphate-buffered saline. On the other hand, changes in the near-ultraviolet region suggested a modification of tertiary structure in the pure deep eutectic solvent (Sanchez-Fernandez et al., 2017). Bovine serum albumin in pure solvents was irreversibly denatured by heating to $80^{\circ} \mathrm{C}$, but the results in water are not reported. As far as lysozyme was concerned, its secondary structure of a mixture of $\alpha$-helix and $\beta$-sheet was not modified in the chosen deep eutectic solvents: choline chloride with glycerol or urea. Small-angle neutron scattering was used to get a better impression of the 
protein conformation in solution. This showed that the globular shape of bovine serum albumin became less symmetrical in pure deep eutectic solvent, indicating that the solvation of the protein was modified in this solvent. On the other hand, when a hydrated deep eutectic solvent was used, the results were not different from pure water. This was interpreted as water forming a shell around the protein, preventing direct interaction with the deep eutectic solvent. In the case of lysozyme, the protein was found to be only partially folded in the deep eutectic solvent, irrespective of whether it contained glycerol or urea. This might not have been expected because high concentrations of urea denature proteins.

Another study of lysozyme structure in deep eutectic solvents was carried out by Esquembre et al. (Esquembre et al., 2013). They also used circular dichroism and also followed the intrinsic fluorescence of tryptophan residues that also gives information about folding and unfolding of the protein. In this study, the deep eutectic solvents were composed of choline chloride with either glycerol or urea in a 2:1 molar ratio. Tryptophan fluorescence of lysozyme was slightly blue shifted in solvents compared with buffer solution, whereas denatured lysozyme shows a red shift. Heating of lysozyme caused unfolding in all solvents but monitoring of the mean fluorescence energy indicated different processes in buffer and in deep eutectic solvent solution: in the latter the protein appeared to pass through a number of intermediate states. These states were examined by means of circular dichroism spectra. Differences in the near-ultraviolet region were recorded as a function of temperature and revealed that modifications in the tertiary structure began to occur at a lower temperature for the deep eutectic solvent containing urea than for the deep eutectic solvent with glycerol or with buffer. While the thermally induced unfolding of lysozyme was completely reversible in buffer, it was only partially so in the deep eutectic solvent with glycerol and irreversible in the urea-containing deep eutectic solvent. The biological activity of lysozyme was also tested in media containing various proportions of the choline chloride: glycerol solvent, by its capacity to lyse a Gram-positive bacterium. The speed of bacterial degradation decreased as the proportion of the solvent increased. The authors concluded that a detailed characterisation of the system is necessary before deep eutectic solvent can be used as a solvent for biocatalysis (Esquembre et al., 2013).

Harifi-Mood et al. studied the structure and activity of the enzyme catalase from bovine liver in two deep eutectic solvents: choline chloride:glycerol 1:2 and choline chloride:urea 1:2 (Harifi-Mood et al., 2017). Fluorescence spectroscopy and circular dichroism indicated that the secondary structure of the protein was modified in the deep eutectic solvents, more in the glycerol-containing one than in the urea-based one. The enzymatic activity was slightly 
reduced in the deep eutectic solvents compared with phosphate buffer, but the binding affinity of the substrate was increased. The use of deep eutectic solvents as solvents for the bacterial enzyme laccase was investigated by Khodaverdian et al. (Khodaverdian et al., 2018). They used natural deep eutectic solvents based on choline or betaine, the latter leading to better preservation of enzyme activity. In particular, a deep eutectic solvent composed of sorbitol, betaine and water in equimolar proportions improved the stability of the enzyme at high temperature compared with aqueous buffer. Once again, the intrinsic fluorescence of tryptophan residues was used to monitor structural changes in the protein.

The influence of choline-based ionic liquids on the catalytic activity of lipase from Aspergillus niger was investigated by Nascimento et al. (Nascimento et al., 2019). At low concentrations, all the ionic liquids tested (choline, choline acetate, choline propanoate, choline butanoate, choline pentanoate and choline hexanoate) allowed the activity to be maintained, or even enhanced. However, higher concentrations of the anions with longer alkyl chains (pentanoate and hexanoate) inhibited enzyme activity, suggesting that these formulations could be useful in modulating lipase activity in vivo.

In living cells, protein folding and re-folding is facilitated by other proteins known as chaperones that play an important role in the response of the cell to stress. The fact that many of the components of deep eutectic solvents are found in cells and are related to survival under extreme condition led Niknaddaf et al. to put forward the hypothesis that these solvents could act as chemical chaperones (Niknaddaf et al., 2018). They conducted experiments to test this using a model of lysozyme aggregation by the reducing agent dithiothreitol. They observed that $20 \%$ of choline chloride:urea solvent in water completely inhibited this aggregation, which is brought about by the reduction of disulphide bonds in the protein. This might appear to be contradictory with the results of Esquembre et al. above (Esquembre et al., 2013); however, the mechanism of denaturation was different. They also looked at refolding by dilution after denaturation with guanidinium chloride. The presence of the choline chloride:urea solvent in the dilution buffer reduced aggregation compared with simple buffer. Monitoring of the intrinsic fluorescence of tryptophan confirmed that the solvents promoted correct refolding. The biological activity of the enzyme, again measured by the ability to lyse bacteria, was also recovered better when the solvent was present in the renaturation solution (Niknaddaf et al., 2018).

In two articles published in 2018, Silva et al. another aspect of lysozyme behaviour was considered. In this work, they were attempting to produce nanofibers from the protein; that is, promoting its denaturation and aggregation. Protein nanofibers have a number of applications 
in biotechnology, for example in tissue engineering and biosensors, particularly when combined with polymers. In one study, they observed that hen egg white lysozyme fibrillation was considerably faster in ionic liquids than in water or $\mathrm{pH} 2$ buffer. Various spectroscopic and microscopic techniques revealed nanofibers of up to $1 \mu \mathrm{m}$ in length, with a diameter depending on the ionic liquid used (Silva et al., 2018a). The presence the acetate anion was found to favour the formation of $\beta$-sheet structures which are more inclined to aggregate and produce fibrils. In another work, acetate and other carboxylic acids were used in combination with choline chloride to form deep eutectic solvents that were then used as a medium for the formation of lysozyme nanofibers in acidic solution (Silva et al., 2018b). The dimensions of the fibres depended on the nature of the carboxylic acid, the longest fibres being obtained with lactic acid. Again, the formation was rapid, complete within a few hours. The nanofibers so generated were incorporated into carbohydrate-based films, where they increased the tensile strength.

$\mathrm{Qu}$ et al. have investigated the possibility of creating materials for drug delivery from proteins dissolved in deep eutectic solvents (Qu et al., 2019). They tested the plasticizing properties of deep eutectic solvents, in particular "Glyceline", choline chloride:glycerol 1:2, with two plant-derived globular proteins, zein from maize and soy protein. Although the solvents modified the properties of the proteins, the resulting materials were not as strong and ductile as those using PEG or fatty acid modifiers. On the other hand, when gelatine, a fibrous protein, was incorporated into Glyceline mixtures, a material with high ductile strength was obtained. The choline chloride could be replaced by imipramine hydrochloride, forming a therapeutic deep eutectic solvent, and patches could be prepared that increased the penetration of the drug into bovine skin.

Another enzyme whose activity has been improved by incorporation into a deep eutectic solvent is versatile peroxidase, a heme peroxidase of fungal origin. It has potential industrial applications for which an alternative to organic solvents would be desirable. Thus, a deep eutectic solvent composed of choline chloride and glycerol (1:2) was tested (Mamashli et al., 2018). The activity of the enzyme at neutral $\mathrm{pH}$ was higher in the solvent-buffer mixtures than in buffer alone. A number of techniques, including circular dichroism and fluorescence spectroscopy, showed changes in protein structure in the deep eutectic solvent, with exposure of hydrophobic regions and rearrangement of the heme group. Furthermore, the thermal stability of the enzyme was improved in deep eutectic solvent.

Interferon- $\alpha 2$ (IFN- $\alpha 2)$ is a cytokine with several therapeutic applications in the treatment of cancer and liver disease. However, therapeutic proteins are notoriously difficult to formulate, 
store and handle. Lee et al. investigated the formulation of this protein in several natural deep eutectic solvents with particular focus on its thermal stability (Lee et al., 2018). An equimolar mixture of choline chloride and fructose was found to preserve the biological activity of Interferon- $\alpha 2$ during a 2 -h incubation at temperatures of $37^{\circ} \mathrm{C}, 50^{\circ} \mathrm{C}$ and even $70^{\circ} \mathrm{C}$. Circular dichroism and fluorescence spectroscopy experiments showed that the protein conformation was preserved when it was heated in the choline chloride:fructose deep eutectic solvents, in contrast to the modifications observed when it was formulated in phosphate-buffered saline (PBS). This opens up the way to formulations that do not need a strict cold chain to preserve their activity.

As discussed below, proteins, and in particular insulin, have been included in deep eutectic solvents in order to improve their cutaneous, oral or nasal bioavailability (Banerjee et al., 2017; Tanner et al., 2018; Banerjee et al., 2018a; Li et al., 2019).

\subsection{Antimicrobial applications.}

As can be seen from the section on solubilisation of small molecules, a number of antimicrobial agents have been incorporated into deep eutectic solvents. However, beyond this, it has been observed that some deep eutectic solvents formulations themselves have antiseptic or antimicrobial activity in their own right, especially by the topical route. The antimicrobial applications of deep eutectic solvents are summarized in Table 4.

\subsubsection{Deep eutectic solvents with intrinsic antimicrobial activity.}

Zakrewsky et al. provide some convincing evidence that a deep eutectic solvent composed of choline and geranic acid in a 1:2 molar ratio, named CAGE, could act as an efficient antiseptic agent on the skin (Zakrewsky et al., 2016a). They have shown antimicrobial activity against a wide range of bacteria, fungi and viruses, combined with low skin toxicity. An invivo study was carried out on a skin infection with Propionibacterium acnes injected intradermally in rat ears. The choline:geranic acid solvent was much more effective than clindamycin in saline in reducing ear thickness and reaching bacteria in deeper skin layers. This development of a cheap, effective and nontoxic topical antimicrobial formulation has considerable importance given the rise of resistance to current agents and the withdrawal of some compounds because of safety concerns.

This research group has filed several patents with claims concerning the potential of ionic liquids for use on the skin: their lack of irritability and their ability to transport substances through the skin (Zakrewsky et al., 2015; Zakrewsky et al., 2016b; Kellar et al., 2018). In 
particular, the latest patent application (Kellar et al., 2018) refers to the role of ionic liquids in wound healing as a result of their ability to inhibit biofilm formation and to control pathogen growth. The "CAGE" formulation of choline and geranic acid figures prominently in the examples cited. A recent study has used some physicochemical techniques to probe the mechanism of action of the choline:geranic acid solvent (Ibsen et al., 2018). Molecular dynamic simulations were used to understand how the "CAGE" components might interact with the membrane of Escherichia coli. The choline:geranate pair seems to be able to penetrate through the lipopolysaccharide (LPS) layer and bind to the negatively charged membrane. Membrane disruption could be observed in "CAGE"-treated cells by scanning electron microscopy. Fourier-transform infrared spectroscopy with attenuated total reflection demonstrated increased lipid content in treated cells. Importantly, Escherichia coli cells did not develop resistance after multiple or prolonged exposures to the choline:geranic acid solvent.

Another mechanism of activity of deep eutectic solvents against bacteria was investigated by Sadaf et al. (Sadaf et al., 2018). In in-vitro studies, they looked at the ability of a formulation that they named "maline", composed of malonic acid and choline chloride in a 2:1 molar ratio to inhibit the activity of an extracellular enzyme, $\beta$-lactamase from Bacillus cereus. As in the studies on lysozyme reported above, circular dichroism and intrinsic fluorescence were used to monitor protein structure. This showed a transition of $\alpha$-helix to random coil in the presence of maline, together with fluorescence quenching that could have been due to loss of the tertiary structure of the protein.

The antimicrobial activity of a number of natural deep eutectic solvents was tested towards several bacterial species, as well as a yeast strain and three human cell lines by Radošević et al. (Radošević et al., 2018). The highest activity towards bacteria was obtained with deep eutectic solvents containing organic acids - oxalic, malic and citric. The yeast Candida albicans was quite resistant to these solvents. They also recorded cytotoxic effects towards human tumour cells lines HeLa and MCF-7 with a choline chloride:oxalic acid deep eutectic solvent while a normal cell line, HEK293T, was more resistant. The antioxidant capacity of the deep eutectic solvents was measured by their capacity to absorb oxygen radicals. Most of the solvents tested had oxygen scavenging properties. One deep eutectic solvent, composed of betaine, malic acid and proline, stimulated mammalian cell growth while having strong antioxidant properties.

Recently, Silva et al. investigated the antimicrobial properties of deep eutectic solvents formed entirely from fatty acids, combining capric acid with other saturated fatty acids of 
longer chain length (Silva et al., 2019). They observed activity against gram-positive bacteria and Candida albicans, particularly with a capric acid:lauric acid formulation. A significant result is that these deep eutectic solvents could promote the detachment of Escherichia coli biofilms (Figure 5).
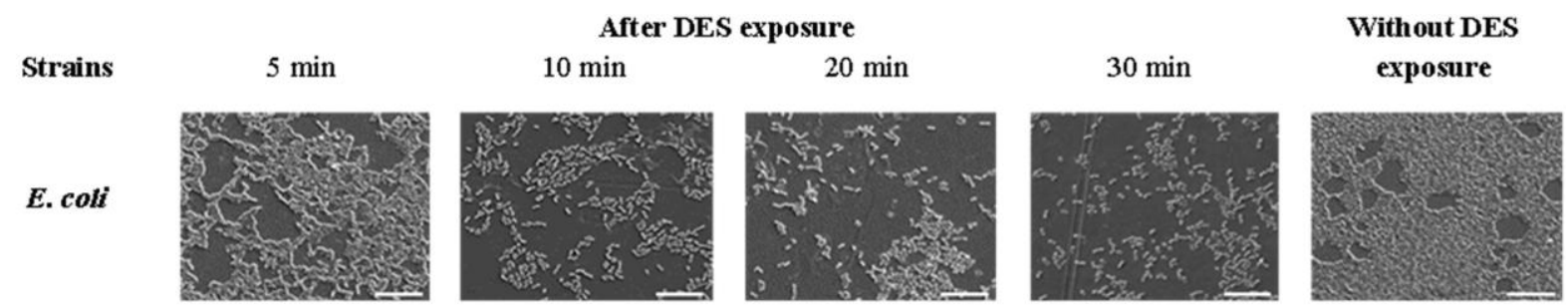

MRSA
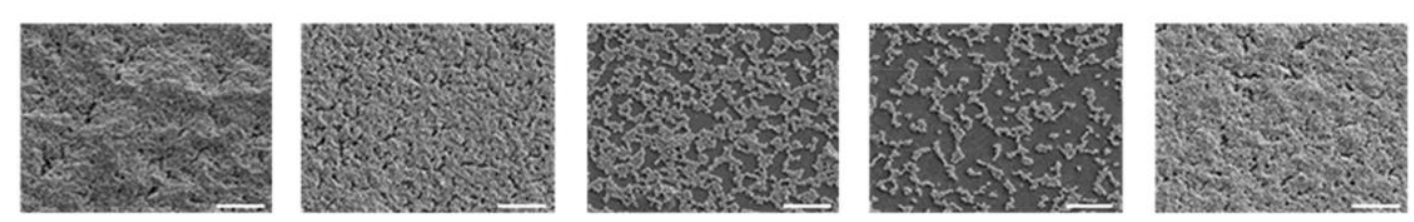

C. albicans
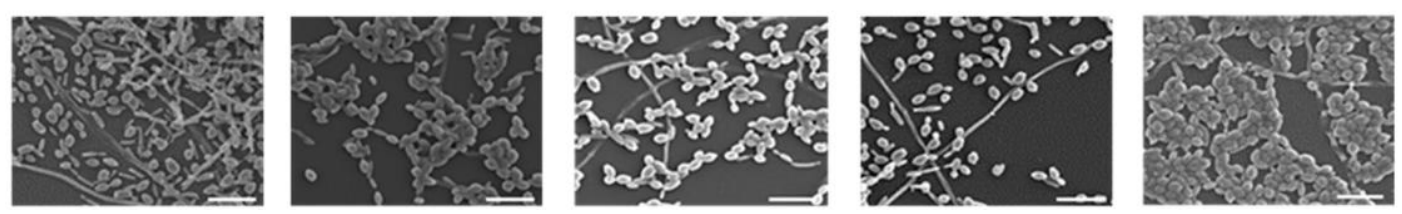

Figure 5. SEM images of biofilms from three different microorganisms (Escherichia coli, methicillin-resistant Staphylococcus aureus and Candida albicans) seeded onto cover slips after various times of exposure to a capric acid:lauric acid formulation (Silva et al., 2019; reprinted with permission of Elsevier).

\subsubsection{Therapeutic deep eutectic solvents for applications in the oral cavity.}

As mentioned above, Lim et al. formed a complex between erythritol and betaine in an attempt to treat biofilms in the oral cavity (Lim et al., 2017). The extracellular matrix secreted by the bacteria in these biofilms makes them extremely resistant to antibiotics. Detachment of Streptococcus mutans biofilms was observed in an in-vitro assay was observed after application of the betaine:erythritol $(2: 1)$ mixture, but not with the components separately. Measurements by atomic force microscopy showed a reduction in the adhesive strength of the biofilm after contact with the betaine-erythritol mixture. It was observed that the waterinsoluble extracellular polysaccharide could be dissolved in this mixture. These results are encouraging for the treatment of dental plaque because the constituent molecules are nontoxic. In a related study, the same group observed activity against biofilms of a complex formed between erythritol and zinc chloride (Lim et al., 2018). The complex was able to interfere with intra- and inter-molecular bonds in the exopolysaccharide. 
Wang et al. also used a deep eutectic solvent-based approach to dental treatment (Wang et al., 2017). A mixture of benzalkonium chloride and acrylic acid could be incorporated into dental resins without altering their mechanical properties, while benzalkonium chloride alone compromised the strength of the resin during storage. The antibacterial activity of these materials was tested by placing discs in agar plates inoculated with Streptococcus mutans or Staphylococcus aureus. The deep eutectic solvent was as effective as benzalkonium chloride alone in controlling bacterial growth. The toxicity towards host cells was tested using the osteoblast line MC3T3-E1 and the 3-(4,5-dimethylthiazol-2-yl)-2,5-diphenyltetrazolium bromide (MTT) assay. Cells cultivated with the composite containing the solvent did not show any decrease in viability compared with control cells, while the composite containing benzalkonium chloride alone reduced their viability by about $50 \%$.

\subsubsection{Formulation of conventional antibiotics in deep eutectic solvents.}

Santos et al. formulated two molecules that are potentially active in tuberculosis: L-arginine and ethambutol, as deep eutectic solvents with citric acid but did not study the antimicrobial activity (Santos et al., 2019). On the other hand, Aroso et al. showed that the activity of benzoic acid and phenylacetic acid against both Gram-negative and Gram-positive bacteria was comparable to that of the free drug when they were prepared as deep eutectic solvents with menthol (Aroso et al., 2016).

The stability of two $\beta$-lactam antibiotics, clavulanic acid and imipenem, was improved by dissolution in a deep eutectic solvent composed of betaine and urea (Olivares et al., 2018). Their antimicrobial activity was determined in vitro by both a limiting dilution method to obtain the minimum inhibitory concentration (MIC) and a disk diffusion assay where the formulations were incorporated into cellulose disks and placed on agar plates containing the microorganisms. The test bacteria used were Escherichia coli and Pseudomonas aeruginosa. When freshly prepared solutions were used, the minimum inhibitory concentration of both antibiotics was identical in aqueous solution and in the solvents. However, when the formulations were kept at $25^{\circ} \mathrm{C}$ for 7 days before adding them to the bacteria the minimum inhibitory concentration of the water solution of imipenem increased at least 32-fold and that of aqueous clavulanic acid doubled, whereas no changes were observed for the deep eutectic solvents compared to a fresh preparation. These results are in agreement with stability studies. The disk assay was used because it allowed the deep eutectic solvent to be added to the bacterial cultures without dilution that could perturb the solvent structure. The size of the ring of growth inhibition of Pseudomonas aeruginosa was similar for antibiotics in aqueous 
solution and in the deep eutectic solvents, showing that they remained fully bioavailable in the latter formulation. This opens up possibilities for the use of these solvents in sustained release formulations without loss of antibiotic activity.

\subsubsection{Formulation of photosensitizers in deep eutectic solvents for} antimicrobial activity.

As described above, deep eutectic solvents have been used to improve the solubility and stability of photosensitising compounds and the resulting formulations have been used for antimicrobial photodynamic therapy. This is reported in a series of articles and a patent application from the group of Tønnesen and Wikene (Wikene and Tønnesen, 2016). The first compound to be used was the small, naturally occurring molecule curcumin (Wikine et al., 2015a). Curcumin in a deep eutectic solvent composed of maleic acid and choline chloride in 1:3 molar ratio was phototoxic towards Escherichia coli at a concentration of $1.25 \mu \mathrm{M}$, lower than any previously reported result. At this concentration, there was no contribution of the toxicity of the deep eutectic solvent itself.

Two porphyrin-based photosensitisers were formulated in a similar way. meso-tetra-(4carboxyphenyl)-porphine (TCPP) is an anionic porphyrin that could be solubilized in acidic deep eutectic solvents: citric acid:sucrose 1:1, DL-malic acid:D-fructose:D-glucose 1:1:1 and choline chloride:xylitol 5:2, with improved photostability compared with methanolic solution (Wikene et al., 2016). The phototoxicity of these preparations were tested against both Grampositive (Enterococcus faecalis, Staphylococcus aureus) and Gram-negative (Escherichia coli) bacterial species. Before testing the phototoxicity of meso-tetra-(4-carboxyphenyl)porphine, it was necessary to establish the photo- and dark toxicity of the deep eutectic solvent and define the dilution at which the effects of the medium were not significant. In these conditions, meso-tetra-(4-carboxyphenyl)-porphine in citric acid:sucrose or malic acid:fructose:glucose was much more phototoxic to all three bacterial species than a solution in ethanol. A neutral porphyrin, meso-tetra(4-hydroxyphenyl)porphine (THPP) was also formulated in this way (Wikene et al., 2015b). Two deep eutectic solvents, citric acid:sucrose 1:1 and D-glucose:DL-malic acid 1:1, were chosen for tests of phototoxicity against Enterococcus faecalis and Staphylococcus aureus. These solutions showed much higher antibacterial phototoxicity than a solution of meso-tetra(4-hydroxyphenyl)porphine in phosphate-buffered saline. In a subsequent study (Wikene et al., 2017) extended the observations to four bacterial species (Escherichia coli, Staphylococcus epidermidis, Pseudomonas aeruginosa, Klebsiella pneumoniae) as well as a fungal pathogen (Candida 
albicans). In these experiments, citric acid:sucrose 1:1 and DL-malic acid:D-fructose:Dglucose 1:1:1 were the chosen deep eutectic solvents. meso-tetra(4-hydroxyphenyl)porphine in the deep eutectic solvents was much more phototoxic towards Escherichia coli than mesotetra(4-hydroxyphenyl)porphine in phosphate-buffered saline. Similar results were obtained with Pseudomonas aeruginosa and Staphylococcus epidermidis. Klebsiella pneumoniae and Candida albicans were less sensitive.

\subsubsection{Molecular imprinting.}

A different approach was recently described by Fu et al. (Fu et al., 2019). They used a deep eutectic solvent composed of choline chloride and acrylic acid to produce a molecularly imprinted polymer designed to selectively extract $\beta$-lactoglobulin from complex mixtures. The polymer was formed on a base of molybdenum disulfide $\left(\mathrm{MoS}_{2}\right)$ containing some iron oxide nanoparticles $\left(\mathrm{Fe}_{3} \mathrm{O}_{4}\right)$ to allow the polymer to be manipulated using an external magnetic field. The deep eutectic solvent was polymerized in the presence of the protein using ethylene glycol dimethacrylate to crosslink acrylic acid. The resulting poly(ChCl-AA deep eutectic solvent)@ $\mathrm{Fe}_{3} \mathrm{O}_{4} @ \mathrm{MoS}_{2}$ was able to selectively extract $\beta$-lactoglobulin from milk, but also showed antibiotic properties. The growth of Staphylococcus aureus, Escherichia coli and Bacillus subtilis was retarded in the presence of the polymeric material. However, an inverse effect was obtained with Pseudomonas fluorescens. The growth of bacterial on biomaterials always poses a problem for their use, so these results are encouraging.

\subsection{Cutaneous applications.}

Ionic liquids and deep eutectic solvents have great potential for topical application to the skin, because of their low toxicity and their rheological properties. Furthermore, there is evidence that these formulations can act as promoters of absorption across the outer layers of the skin and help to deliver active substance into and across the skin. Early work by Stott et al. showed that forming eutectics between ibuprofen and various terpenes could enhance their penetration across human epidermis (Stott et al., 1998).

Transdermal penetration enhancement by deep eutectic solvents was claimed by Zakrewsky et al. in 2014 and in several patents (Zakrewsky et al., 2015; Zakrewsky et al., 2016b; Kellar et al., 2018), with particular reference to treating infections with microbial biofilms in the skin (Zakrewsky et al., 2014). Skin penetration was first determined using radiolabelled mannitol as a model drug and pig skin in Franz diffusion cells. One formulation in particular, a mixture of choline chloride and the geranate anion, was able to promote penetration into the epidermis 
and dermis. A similar result was obtained with the antibiotic cefadroxil incorporated into the deep eutectic solvent. The efficacy of this deep eutectic solvent, with or without antibiotic, was tested on a biofilm formed by Pseudomonas aeruginosa in simulated wounds in an invitro human skin model. The choline chloride:geranate deep eutectic solvent alone caused a very significant reduction in bacterial viability that was further decreased by the inclusion of a related antibiotic (ceftazidime), whereas the ceftazidime in saline had only a small effect. Finally, it was important to assess the tolerance of the skin to deep eutectic solvent application. This was done using Fourier transform infrared spectroscopy to monitor changes in stratum corneum structure in full thickness pig skin. The use of the choline chloride:geranate deep eutectic solvent did not provoke any significant changes (Zakrewsky et al., 2014).

Santos de Almeida et al. also investigated the potential of deep eutectic solvents (ionic liquids as they call them) for cutaneous applications and in particular compared imidazole and choline as the hydrogen bond acceptor (Santos de Almeida et al., 2017). They chose two model drugs: caffeine and salicylic acid and studied their permeation through full thickness pig skin in Franz cells under occlusive conditions as well as the toxicity towards the human HaCaT keratinocyte cell line, using the 3-(4,5-dimethylthiazol-2-yl)-2,5-diphenyltetrazolium bromide (MTT) reduction assay as the endpoint. As reported above, an increase in caffeine solubility of 2-3 times was observed with choline-based formulations while the increases in salicylic acid solubility were more modest. On the other hand, imidazole-based formulations did not increase drug solubility. Permeation across pig skin from saturated solutions of the drug in 5:95 deep eutectic solvent:water was studied. The imidazole-based formulations increased passage across the skin while choline-based ones had no promoting effect. This might have been due to a surfactant effect of imidazole side chain. Reduced passage across the skin would be an advantage for an activity in the skin without systemic toxicity. The choline-based formulations were less toxic than the imidazole-based ones.

Choline:glutamine and choline:phenylalanine deep eutectic solvents loaded with caffeine were formulated as oil-in-water emulsions and gels suitable for skin applications. Emulsions containing the deep eutectic solvents had lower viscosity than a simple caffeine-containing emulsion and needed more surfactant for stability. However, the presence of the deep eutectic solvents prevented the crystallization of caffeine within the emulsion. A similar observation was made when gels containing caffeine were prepared from Carbopol® 940. Gel stability was not compromised by the presence of the deep eutectic solvent (Santos de Almeida et al., 2017). 
As well as their possible applications for the cutaneous delivery of small molecules, deep eutectic solvents have potential for the delivery of proteins to the skin. Banerjee et al. observed that the choline:geranate (1:2) solvent, which they refer to as CAGE formulation, could promote the topical delivery of proteins as varied as bovine serum albumin, ovalbumin and insulin (Banerjee et al., 2017). Labelled proteins were found to penetrate pig skin, reaching the epidermis and the dermis and passing into the acceptor compartment. Confocal microscopy allowed the penetration to be visualized. Fourier transform infrared spectroscopy revealed that the choline:geranic acid formulations modified some peaks in a way that could be interpreted as lipid extraction from the skin. Circular dichroism studies of the secondary structure of insulin showed that the $\alpha$-helical content of the protein was not affected by incorporation into the deep eutectic solvents. Finally, the effect of insulin solubilised in choline:geranic acid solvent on the blood glucose levels of non-diabetic rats was tested. Application of insulin in choline:geranic acid formulation onto the skin resulted in a fall in blood glucose that was more sustained than that obtained after an injection of insulin (although the injected dose was $1 \mathrm{U} / \mathrm{kg}$ while the topical dose was $25 \mathrm{U} / \mathrm{kg}$ ). Choline:geranic acid solvent alone or insulin in buffer applied to the skin had no effect.

In a later study, the solvent formulation was studied in more detail by varying the ratio of choline to geranic acid from 1:4 to 2:1 (Tanner et al., 2018). Nuclear magnetic resonance spectroscopy was used to map the interactions between the protons in the two components and this was found to differ as the proportions changed. This would modify the ability of the solvent to accommodate solutes and allow the composition to be tailored for different types of molecules. Both the viscosity and conductivity of the formulation decreased as the proportion of geranate increased. The thermal stability of the formulations was quite similar over the different ratios, with temperatures of decomposition of 169 to $210^{\circ} \mathrm{C}$. As in previous articles, Fourier-transform infrared spectroscopy was used to assess the impact of the deep eutectic solvent on stratum corneum structure, looking at peak height between 2800 and $3000 \mathrm{~cm}^{-1}$ that show the vibrations in lipid bonds. A decrease in peak height suggests that deep eutectic solvent can extract lipids, and as the solvent becomes more hydrophobic, with a higher proportion of geranate, this effect is more pronounced. Finally, the different formulations were tested for their ability to promote the passage of fluorescently labelled insulin across pig skin in a diffusion cell. The formulations with a higher proportion of geranate (1:2 and 1:4) showed the presence of the protein in the stratum corneum, epidermis and dermis, while for the 1:1 and 2:1 formulations, and for phosphate-buffered saline showed fluorescence restricted to the stratum corneum (Figure 6). 

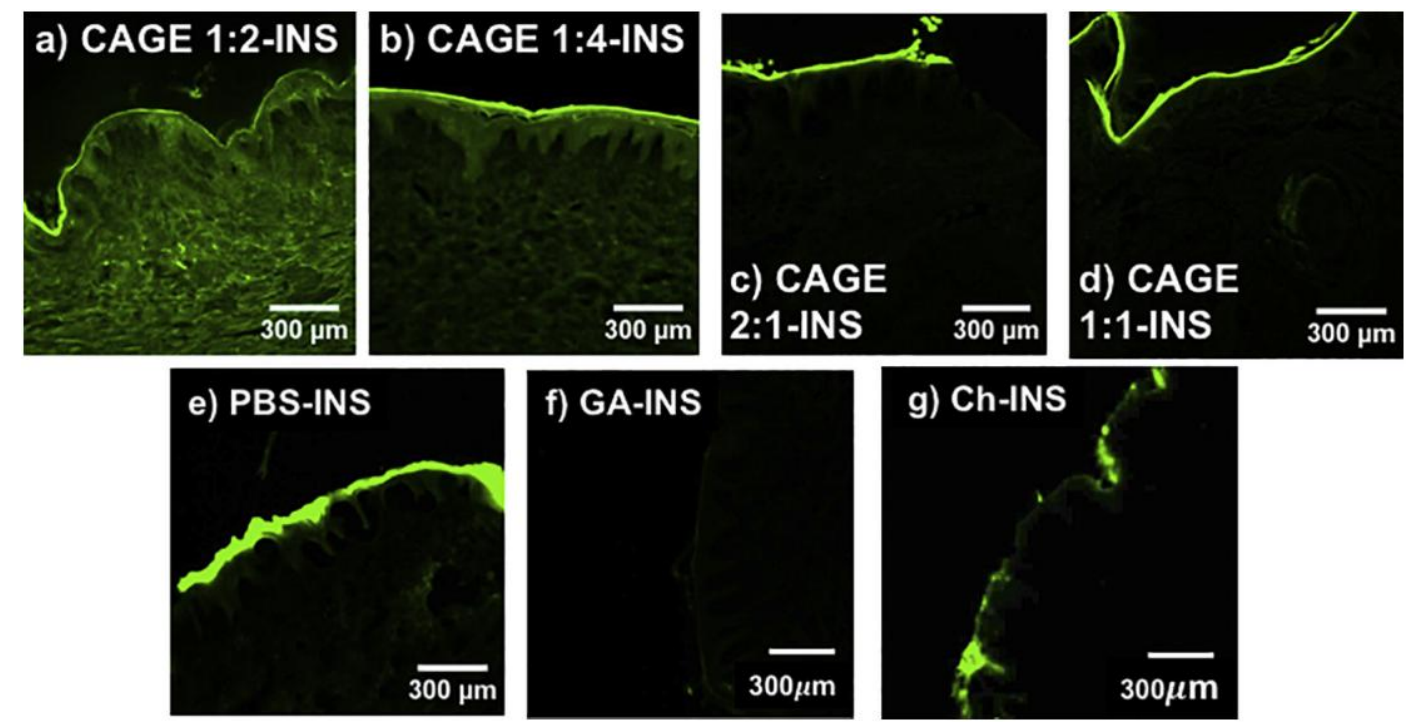

Figure 6. Confocal microscopy of porcine skin after application of FITC-insulin dissolved in a) 1:2 CAGE, b) 1:4 CAGE, c) 2:1 CAGE, d) 1:1 CAGE, e) PBS, f) geranic acid, and g) choline bicarbonate (Tanner et al., 2018; reprinted with permission of Elsevier)

The "CAGE" formulation was also employed for a low molecular weight glucose lowering agent, the flavonoid nobiletin (Hattori et al., 2019). The transdermal passage of this molecule was significantly increased by the use of this solvent and plasma concentrations were enhanced compared with the drug formulated in aqueous buffer or ethanol. Lowering of blood glucose concentrations was observed after transdermal administration to normal rats (Hattori et al., 2019).

A further work aimed at elucidating general principles for transdermal deep eutectic solvent formulation employed two model molecules, acarbose and ruxolitinib, as examples of hydrophilic and hydrophobic drugs respectively (Tanner et al., 2019). Different choline-togeranic acid proportions were used, as well as alternative carboxylic acids to replace geranic acid. The ability of the solvent systems to deliver the active molecules across skin in vitro was correlated with 2D nuclear magnetic resonance studies. It was observed that the transdermal transport capacity of the deep eutectic solvent was inversely related to the strength of the inter-ionic interactions in the solvent. As a result, a deep eutectic solvent containing citronellic acid was found to be the optimal vehicle for ruxolitinib.

Based on the body of work accumulated with the "CAGE" solvent, Qi and Mitragotri have recently published a mechanistic study (Qi and Mitragotri, 2019). They measured the skin penetration of fluorescent dextran of different molecular weights and concluded that for 
molecules up to 150 kilodaltons, transport was enhanced irrespective of molecular size. Combined with their observations on lipid extraction, they concluded that the "CAGE" formulation creates a more favourable environment for diffusion in the skin that does not rely on physiological transport pathways (Qi and Mitragotri, 2019).

The use of ionic liquids and deep eutectic solvents for transdermal applications was recently comprehensively reviewed by Sidat et al. (Sidat et al., 2019). In particular, they list some studies in which ionic liquids have been used in synergy with conventional chemical penetration enhancers.

Table 5 provides a summary of work done on the transdermal applications of deep eutectic solvents.

\subsection{Oral applications.}

After the observations on the transcutaneous passage of insulin, the effect of formulation in deep eutectic solvents on its oral bioavailability was investigated (Banerjee et al., 2018a). Administration of insulin by the oral route has been a goal of pharmaceutical technology for decades, with all the advantages that this would bring in terms of patient compliance. However, the high molecular weight, hydrophilic nature and susceptibility to digestive enzymes of proteins seriously limit its oral bioavailability. Any formulation must be able both to protect the protein in the gastrointestinal tract and promote its absorption across the intestinal epithelium.

The stability of insulin in the choline:geranic acid ("CAGE") deep eutectic solvent was assessed by examining its circular dichroism spectrum after storage at $4^{\circ} \mathrm{C}$ and $25^{\circ} \mathrm{C}$. Insulin formulated in choline:geranic acid solvent was also less susceptible to degradation by trypsin. The protein was found to be stable for four months (Banerjee et al., 2018a). The formulation was administered orally to non-diabetic rats in gastro-resistant capsules and showed a dosedependent glucose-lowering effect, which was not observed with insulin in saline. Histological studies of intestinal samples taken 5 hours after insulin-“CAGE” administration showed no structural damage (Figure 7). This is in accordance with observations made on Caco-2 monolayers in vitro. The transport of fluorescently labelled insulin across these monolayers was also measured and found to be enhanced tenfold by the presence of choline:geranic acid solvent. Since this was accompanied by a reduction in the trans-epithelial electrical resistance, it could be concluded that the deep eutectic solvents could temporarily open tight junctions between the epithelial cells (supplementary material, Banerjee et al., 2018a). Another observation that could shed light on "CAGE" mechanism(s) of action is that 
it reduced the viscosity of the intestinal mucus, which would facilitate contact between the protein and the brush border of the enterocytes.
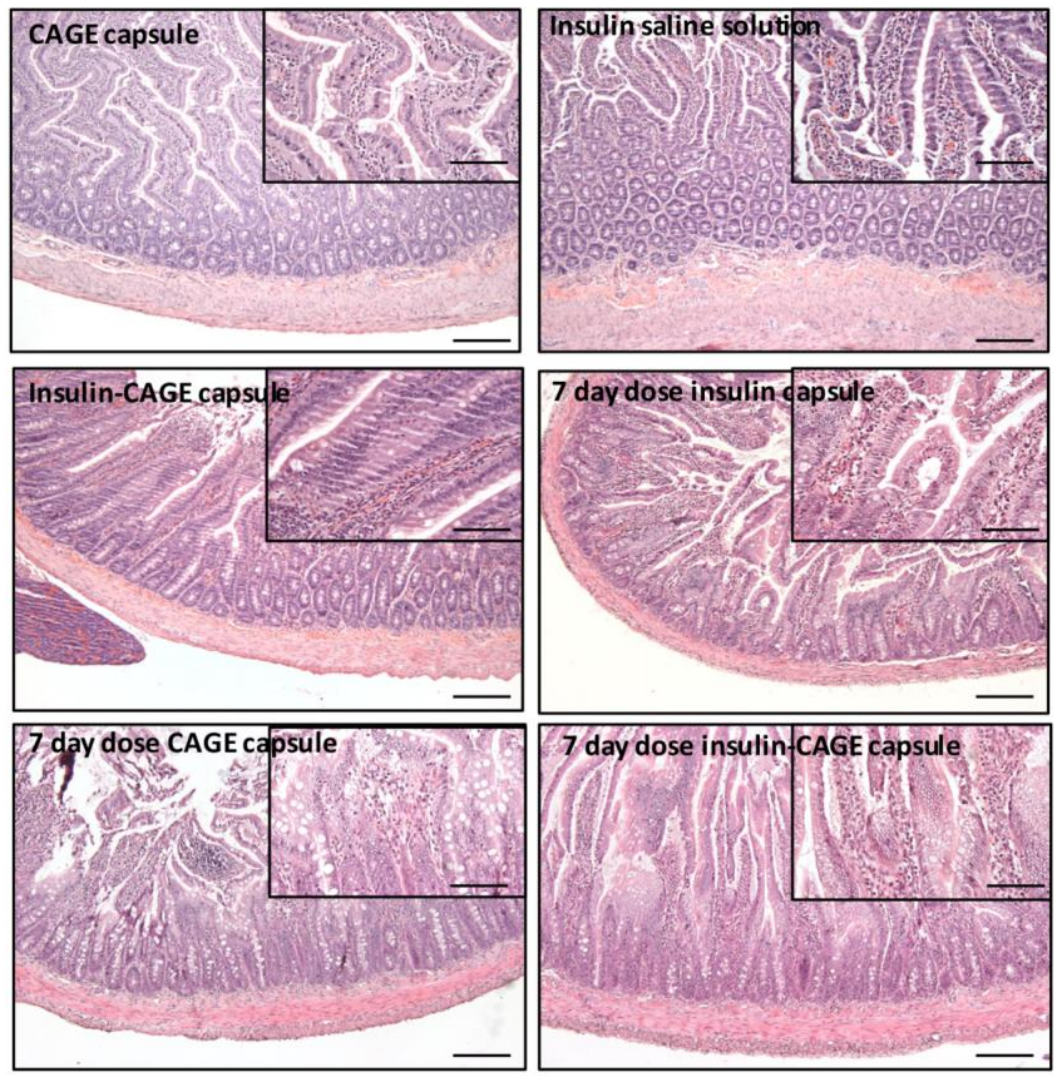

Figure 7. Photomicrographs of hematoxylin and eosin-stained small intestine tissue sections (Scale bar: $200 \mu \mathrm{m}$. Inserts are intestinal sections with scale bar of $50 \mu \mathrm{m}$.). Sections represent oral administration of neat CAGE, insulin-saline or insulin-CAGE capsules after a single dose or after daily dosing for 7 days of insulin, CAGE or insulin-CAGE capsules (Banerjee et al., 2018a, reprinted with permission of Proceedings of the National Academy of Sciences).

The "CAGE" formulation has also been found to exert a biological activity in its own right. Nurunnabi et al; have reported that the formulation can reduce the absorption of fat from the intestine and could therefore counteract obesity. A model fat molecule, docosahexaenoic acid, formed particle in the solvent that were too large to be adsorbed. Rats fed a high-fat diet in conjunction with the "CAGE" formulation gained less weight than those not given "CAGE" (Nurunnabi et al., 2019).

There are also examples of the use of deep eutectic solvents to improve the oral bioavailability of small molecules. Rutin, a disaccharide of quercetin was formulated in a deep eutectic solvent composed of proline and glutamic acid 2:1. A pharmacokinetic study 
was performed in Balb/c mice, comparing the solvent with a suspension in water. The solvent allowed a two-fold increase in the maximum blood concentration $\left(\mathrm{C}_{\max }\right)$ and the area under the curve (AUC), while retarding the time corresponding to the maximum plasma concentration $\left(\mathrm{T}_{\max }\right)$ from 15 minutes with the aqueous suspension to an hour with the deep eutectic solvent (Faggian et al., 2016).

The same team also formulated the naturally occurring alkaloid berberine in deep eutectic solvents for oral applications (Sut et al., 2017). After a solubility study, three deep eutectic solvents were chosen for a pharmacokinetic study: proline:malic acid 1:2, proline:urea 2:1 and proline:malic acid:lactic acid:water 1:0.2:0.3:0.5. All three increased the area under the curve compared with an aqueous suspension, the most effective being the proline:malic acid:lactic acid:water composition (Figure 8).

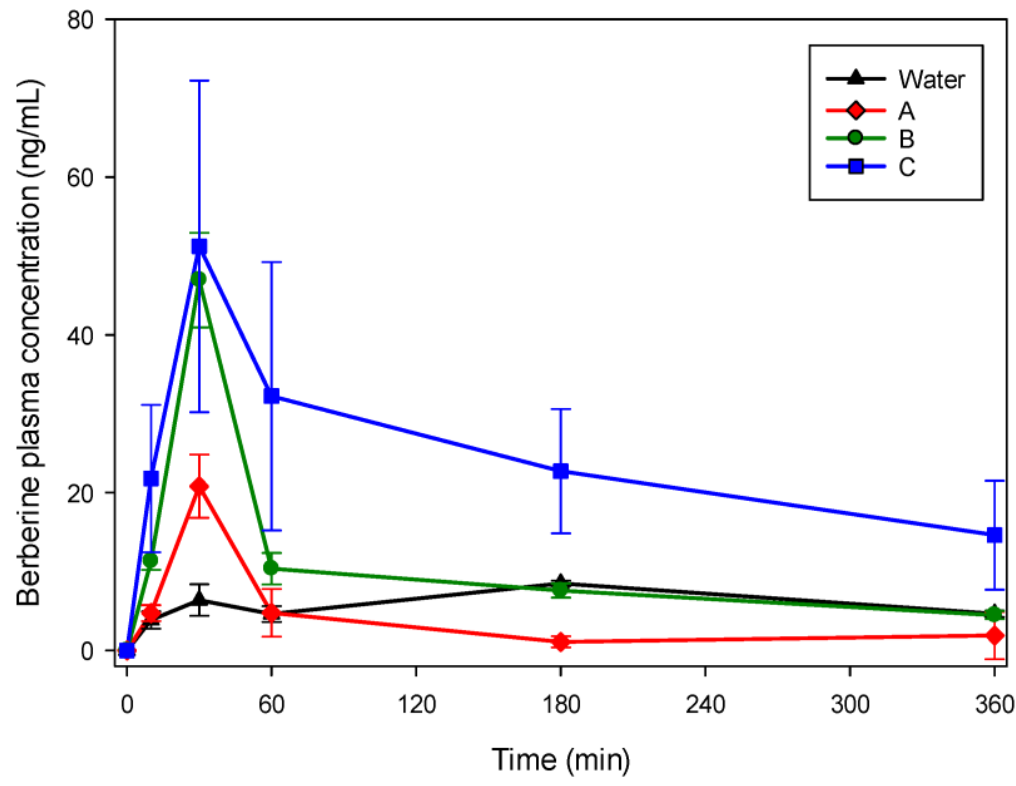

Figure 8. Plasma pharmacokinetics (mean $\pm \mathrm{SD}$ ) of berberine in Balb/c mice following oral administration of $50 \mathrm{mg} / \mathrm{kg}$ in NADES solution $(\mathrm{A}=$ Proline:Malic Acid (1:2), $\mathrm{B}=$ Proline:Urea (2:1), $\mathrm{C}=$ Lactic Acid:Proline:Malic Acid:Water (1:0.2:0.3:0.5)) or in suspension in water (Sut et al., 2017).

Chen et al. have determined the pharmacokinetics and acute toxicity of salvianolic acid B after oral administration within a choline chloride:glycerol (1:2) deep eutectic solvent (Chen et al., 2017). It was clear from the results that this solvent promoted the absorption of the active compound, with a higher maximum plasma concentration achieved early than from an 
aqueous solution, although the areas under the curve and the mean retention time were similar for the two formulations. The prolife of metabolites detected in the blood was also similar. As a preliminary to its use as an oral formulation, Jeliński et al. tested the solubility in synthetic gastro-intestinal medium of curcumin either added as an aqueous solution or in natural deep eutectic solvents formed from choline chloride and various sugars or sugar alcohol (Jeliński et al., 2019b). Presentation of the drug in the form of a natural deep eutectic solvent greatly increased its solubility in both gastric and intestinal media, suggesting that its absorption would be facilitated by this formulation.

\subsection{Nasal applications.}

Nasal administration has also attracted attention as an alternative route for the administration of insulin and other proteins. As for transdermal and oral applications, this route requires a formulation that can promote absorption while remaining nontoxic. With this in mind, Li et al. investigated a formulation of insulin in a deep eutectic solvent composed of chlorine chloride and malic acid (2:1 molar ratio) containing porcine insulin for intranasal administration ( $\mathrm{Li}$ et al., 2019). Circular dichroism studies showed that the structural conformation of the insulin was conserved within the solvent. The release of insulin from the solvent in a Franz diffusion cell was slower than that of the protein from a hydrogel. This could be explained by the limited interaction of the deep eutectic solvent, which had high viscosity, with water. The passage of insulin across ex-vivo nasal mucosa was visualized after fluorescent labelling and the deep eutectic solvent formulation was observed to promote penetration whereas the hydrogel did not. Furthermore, a dose-dependent hypoglycaemic effect was obtained when the deep eutectic solvent was applied intranasally to nondiabetic rats. Histological studies of the nasal epithelium showed no evidence of nasal toxicity (Figure 9; Li et al., 2019). Thus, as for oral and transdermal applications, deep eutectic solvents show promise as vehicles to facilitate protein absorption. 

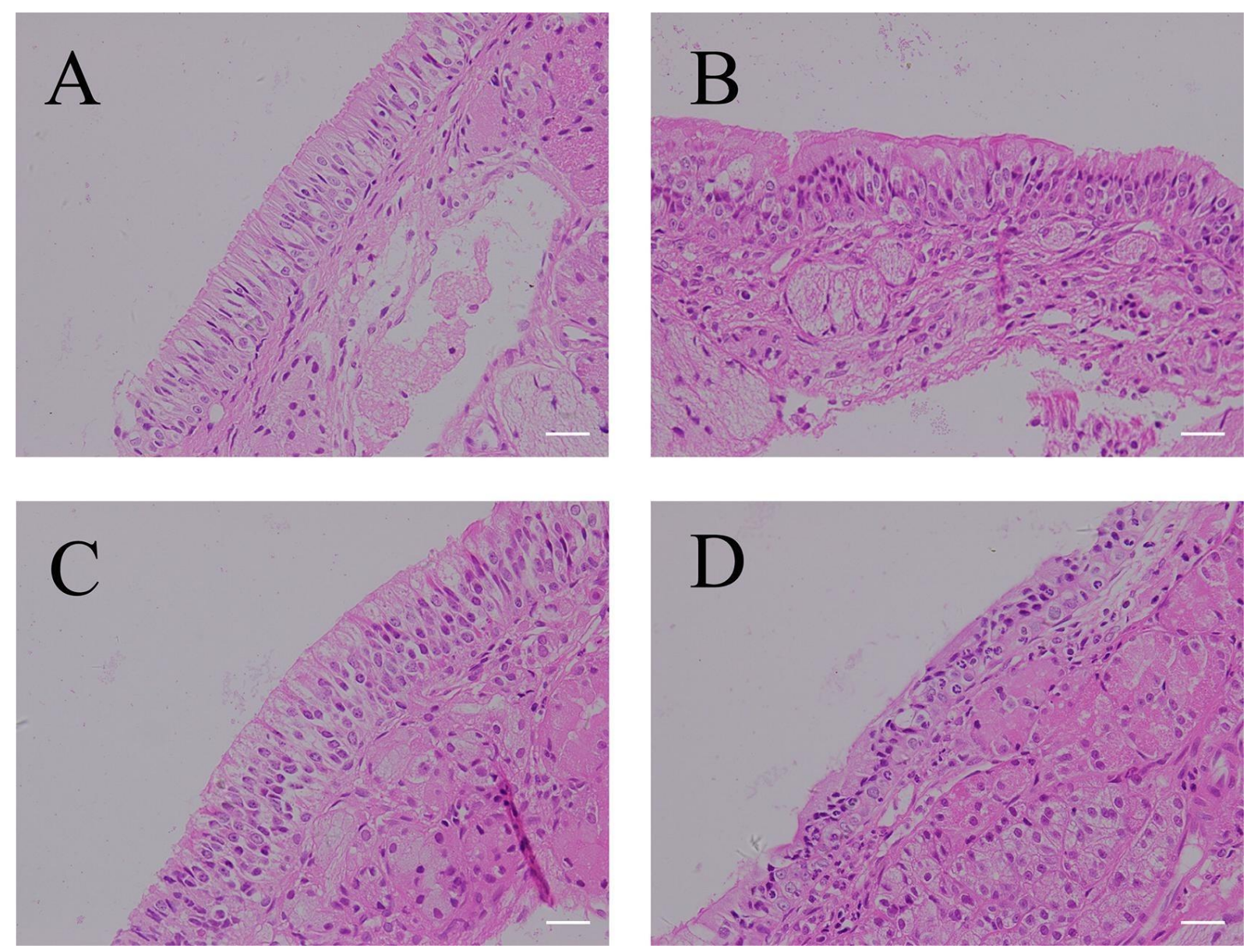

Figure 9. Photomicrographs of hematoxylin and eosin-stained nasal epithelia sections (Scale bar: $25 \mu \mathrm{m}$.). Sections represent nasal administration of (A) normal saline, (B) choline chloride:malic acid DES, (C) insulin-loaded DES or (D) sodium deoxycholate once a day for 7 days (Li et al., 2019, reprinted with permission of Elsevier).

The results obtained with the oral and nasal administration of active molecules in deep eutectic solvents are summarized in Table 6.

\subsection{Applications in formulation for drug delivery and biotechnology.}

As well as specific applications related to particular active molecules, some recent research has covered the contribution that deep eutectic solvents could bring to pharmaceutical technology as a whole. A recent review by Pedro et al. covers the role of deep eutectic solvents and therapeutic deep eutectic solvents containing active molecules in the development of drug delivery systems (Pedro et al., 2019). This report stresses the role of deep eutectic solvents in controlling drug polymorphism and also the ease with which deep eutectic solvent-solubilized molecules can be incorporated into biopolymer systems. Potticary et al., in a study deposited on arXiv.org in 2019, also discuss the role of deep eutectic 
solvents, or deep eutomic solvents as they call them, with respect to drug polymorphism (Potticary et al., 2019). In particular, they investigated the interaction of different polymorphs of paracetamol that can act as a hydrogen bond acceptor with phenol as hydrogen bond donor. By selecting the right deep eutectic solvent composition, the most active form of the drug could be selected at room temperature.

An example of the incorporation of a deep eutectic solvent into a polymeric drug delivery system was given by Aroso et al. who formulated a therapeutic deep eutectic solvent with ibuprofen and menthol that they incorporated into a commercial preparation of corn starch with poly- $\varepsilon$-caprolactone using supercritical carbon dioxide $\left(\mathrm{scCO}_{2}\right)$ technology to provide a controlled release system (Aroso et al., 2015). A review by Barros et al. describes the use of deep eutectic solvents or therapeutic deep eutectic solvents for impregnation of active molecules into polymeric devices using $\mathrm{scCO}_{2}$ (Barros et al., 2017). The plasticizing properties of the deep eutectic solvents allow matrices of higher porosity to be produced.

In a more recent study carried out by Pradeepkumar et al. an anticancer drug, chlorambucil, was chemically modified to allow it to become one component of a deep eutectic solvent that was incorporated into a polymeric system modified with folic acid to target breast cancer cells (Pradeepkumar et al., 2018). Furthermore, a second anticancer drug, doxorubicin, was incorporated into the polymer micelles. Chlorambucil was conjugated with dimethylaminopropanol to form an hydrogen bond acceptor known as CABAL. This was mixed with 1,4-butanediol in various ratios to form deep eutectic solvent. A co-polymer was synthesized from folic acid-modified $\beta$-alanine and poly- $\varepsilon$-caprolactone. When mixed with the optimized deep eutectic solvent, the polymer formed micelles that could then be loaded with doxorubicin. Drug loaded micelles were more cytotoxic to the MDA-MB-231 human breast cancer cell line than to L929 mouse fibroblasts. Finally, tumour volume was reduced in an in-vivo model of rats bearing DMBA-induced mammary tumours when the animals were treated with doxorubicin-loaded polymer micelles. In a later article they used a similar formulation to encapsulate paclitaxel (Pradeepkumar et al., 2019a). After an extensive physico-chemical characterization, the micelles were tested for cytotoxicity to HeLa human cervical cancer cells and normal blood cells. Activity against cancer cells was observed, while there was no toxicity towards the blood cells.

The same team has also produced a polymer-deep eutectic solvent formulation using a choline chloride:xylitol deep eutectic solvent as a medium in which to polymerize 2-hydroxylethyl methacrylate (HEMA) in the form of nanoparticles, which were then loaded with 5- 
fluorouracil (Pradeepkumar et al., 2019b). These nanoparticles were taken up by and showed antiproliferative activity against HeLa cells.

Florindo et al. have prepared a deep eutectic solvent composed of sodium dodecanoate and decanoic acid in the form of a hydrogel with rheological properties suitable for pharmaceutical applications (Florindo et al., 2018).

Deep eutectic solvents also have numerous applications in biotechnology that could lead to the discovery of new drugs or the preparation of new delivery systems. The use of deep eutectic solvents to extract natural products has already been referred to above; for example, the extraction of polyphenols from coffee beans (Benlebna et al., 2018), antioxidants from grape skin (Radošević et al., 2016) and flavonoids from plants (Tang et al., 2016). Furthermore, $\mathrm{Fu}$ et al. have used a deep eutectic solvent as a medium for producing a molecularly imprinted polymer in order to extract $\beta$-lactoglobulin (Fu et al., 2019). Also in the section on the incorporation of high molecular weight compounds into deep eutectic solvents, it has been shown that nanofibers can be produced from lysozyme (Silva et al., 2018a, 2018b) and a pharmaceutically useful material can be created from gelatin in the "Glyceline" deep eutectic solvent (Qu et al., 2019).

It has also been demonstrated in work cited above that the activity of many enzymes can be conserved or even improved in deep eutectic solvents, opening up the way to their use as alternative media for biotransformations. Thus the thermal stability of lysozyme can be increased (Su and Klibanov, 2015), the catalytic activity of catalase (Harifi-Mood et al., 2017), laccase (Khodaverdian et al., 2018) and lipase (Nascimento et al., 2019) was conserved and the biotransformation of steroids by bacteria was efficient (Mao et al., 2019). Finally, Sivapragasam et al. have shown that some choline-based ionic liquids promoted the growth of the yeast Saccharomyces cerevisiae, suggesting that deep eutectic solvents could act as an alternative medium for microbial cultures (Sivapragasam et al., 2019).

\section{Conclusions.}

This chapter shows that deep eutectic solvent-based systems are promising, versatile tools for many formulations destined for various routes of administration, including, but not limited to, oral, dermal and nasal. They provide an alternative to traditional solvents for a wide range of known molecules and could also be applied to new chemical entities and natural products. This could also pave the way for the development of efficient antimicrobial formulations or novel delivery systems of high-molecular weight molecules. However, most research up to this point has focused mainly on the "superiority" aspects of deep eutectic solvents but has 
only briefly considered their potential drawbacks. In fact, stability tests were generally shortterm while the toxicity of deep eutectic solvents was investigated mostly on single cell lines using freshly prepared deep eutectic solvent samples. Therefore, it is essential to study the long-term stability of deep eutectic solvent-based formulations in more depth as well as their chronic and systemic toxicity of these systems before any attempt to commercialize them is made.

\section{Acknowledgments.}

The authors thank the French Embassy in Vietnam for the PhD fellowship of Canh-Hung Nguyen and the French National Research Agency (ANR) for the funding of the project ParasiDES (ANR-19-CE18-0027).

\section{References.}

Abbott AP, Ahmed EI, Prasad K, Qader IB, Ryder KS (2017) Liquid pharmaceuticals formulation by eutectic formation. Fluid Phase Equilib, 448: 2-8. https://doi.org/10.1016/j.fluid.2017.05.009

Abranches DO, Larriba M, Silva LP, Melle-Franco M, Palomar JF, Pinho SP, Coutinho JAP (2019) Using COSMO-RS to design choline chloride pharmaceutical eutectic solvents. Fluid Phase Equilib, 497: 71-78. https://doi.org/10.1016/j.fluid.2019.06.005

El Achkar T, Moufawad T, Ruellan S, Landy D, Greige-Gerges H, Fourmentin S (2020) Cyclodextrins: from solute to solvent. Chem Commun, in press. https://doi.org/10.1039/D0CC00460J

Adawiyah N, Moniruzzaman M, Hawatulaila S, Goto M (2016) Ionic liquids as a potential tool for drug delivery systems. Med Chem Commun, 7: 1881-189. https://doi.org/10.1039/C6MD00358C

Ahmadi R, Hemmateenejad B, Safavi A, Shojaeifard Z, Mohabbati M, Firuzi O (2018) Assessment of cytotoxicity of choline chloride-based natural deep eutectic solvents against human HEK-293 cells: A QSAR analysis. Chemosphere, 209: 821-838. https://doi.org/10.1016/j.chemosphere.2018.06.103

Agatemor C, Ibsen KN, Tanner EE, Mitragotri S (2018) Ionic liquids for addressing unmet needs in healthcare. Bioeng Transl Med, 3: 7-25. https://doi.org/10.1002/btm2.10083 Aroso IM, Craveiro R, Rocha Â, Dionísio M, Barreiros S, Reis RL, Paiva A, Duarte AR (2015) Design of controlled release systems for THEDES-Therapeutic deep eutectic solvents, 
using supercritical fluid technology. Int J Pharm, 492: 73-79. https://doi.org.10.1016/j.ijpharm.2015.06.038

Aroso IM, Silva JC, Mano F, Ferreira AS, Dionísio M, Sá-Nogueira I, Barreiros S, Reis RL, Paiva A, Duarte AR (2016) Dissolution enhancement of active pharmaceutical ingredients by therapeutic deep eutectic systems. Eur J Pharm Biopharm, 98: 57-66. https://doi.org/10.1016/j.ejpb.2015.11.002

Banerjee A, Ibsen K, Iwao Y, Zakrewsky M, Mitragotri S (2017) Transdermal protein delivery using choline and geranate (CAGE) deep eutectic solvent. Adv Healthc Mater, 6: 1601411. https://doi.org/10.1002/adhm.201601411

Banerjee A, Ibsen K, Brown T, Chen R, Agatemor C, Mitragotri S (2018a) Ionic liquids for oral insulin delivery. Proc Natl Acad Sci USA, 115: 7296-7301. https://doi.org/10.1073/pnas.1722338115

Banerjee A, Ibsen K, Brown T, Chen R, Agatemor C, Mitragotri S (2018b) Reply to Rogers and Gurau: definitions of ionic liquids and deep eutectic solvents. Proc Natl Acad Sci USA, 115: E11000-E11001. https://doi.org/10.1073/pnas.1815526115

Barros AA, Silva JM, Craveiro R, Paiva A, Reis RL, Duarte ARC (2017) Green solvents for enhanced impregnation processes in biomedicine. Curr Opin Green Sustain Chem, 5: 82-87. https://doi.org/10.1016/j.cogsc.2017.03.014

Benlebna M, Ruesgas-Ramón M, Bonafos B, Fouret G, Casas F, Coudray C, Durand E, Cruz Figueroa-Espinoza M, Feillet-Coudray C (2018) Toxicity of natural deep eutectic solvent betaine:glycerol in rats. J Agric Food Chem, 66: 6205-6212. https://doi.org/10.1021/acs.jafc.8b01746

Chen J, Li SF, Yao ZF, Yanga DW, Zhang LW (2016) Improved stability of salvianolic acid B from Radix Salviae miltiorrhizae in deep eutectic solvents. Ana Methods, 8: 2502-2509. https://doi.org/10.1039/C5AY03351A

Chen J, Wang Q, Liu M, Zhang L (2017) The effect of deep eutectic solvent on the pharmacokinetics of salvianolic acid B in rats and its acute toxicity test. J Chromatogr B Analyt Technol Biomed Life Sci, 1063: 60-66. https://doi.org/10.1016/j.jchromb.2017.08.016 Choi YH, van Spronsen J, Dai Y, Verberne M, Hollmann F, Arends IWCE, Witkamp GJ, Verpoorte R (2011) Are natural deep eutectic solvents the missing link in understanding cellular metabolism and physiology? Plant Physiology, 156: 1701-1705. https://doi.org/10.1104/pp.111.178426

Colombo Dugoni G, Di Pietro ME, Ferro M, Castiglione F, Ruellan S, Moufawad T, Moura L, Costa Gomes MF, Fourmentin S, Mele A (2019) Effect of water on deep eutectic 
solvent//-cyclodextrin systems. ACS Sustainable Chem Eng, 7: 7277-7285. https://doi.org/10.1021/acssuschemeng.9b00315

Dai Y, van Spronsen J, Witkamp GJ, Verpoorte R, Choi YH (2013) Natural deep eutectic solvents as new potential media for green technology. Anal Chim Acta, 766: 61-68. https://doi.org/10.1016/j.aca.2012.12.019

Dai Y, Witkamp GJ, Verpoorte R, Choi YH (2015) Tailoring properties of natural deep eutectic solvents with water to facilitate their applications. Food Chem, 187: 14-19. https://doi.org/10.1016/j.foodchem.2015.03.123

Duarte AR, Ferreira AS, Barreiros S, Cabrita E, Reis RL, Paiva A (2017) A comparison between pure active pharmaceutical ingredients and therapeutic deep eutectic solvents: solubility and permeability studies. Eur J Pharm Biopharm, 114: 296-304. https://doi.org/10.1016/j.ejpb.2017.02.003

Durand E, Lecomte J, Villeneuve P (2016) From green chemistry to nature: The versatile role of low transition temperature mixtures. Biochimie, 120: 119-123. https://doi.org/10.1016/j.biochi.2015.09.019

Durand E, Lecomte J, Upasani R, Chabi B, Bayrasy C, Baréa B, Jublanc E, Clarke MJ, Moore DJ, Crowther J, Wrutniak-Cabello C, Villeneuve P (2017) Evaluation of the ROS inhibiting activity and mitochondrial targeting of phenolic compounds in fibroblast cells model system and enhancement of efficiency by natural deep eutectic solvent (NADES) formulation. Pharm Res, 34: 1134-1146. https://doi.org/10.1007/s11095-017-2124-4

Esquembre R, Sanz JM, Wall JG, del Monte F, Mateo CR, Ferrer ML (2013) Thermal unfolding and refolding of lysozyme in deep eutectic solvents and their aqueous dilutions. Phys Chem Chem Phys, 15: 11248-11256. https://doi.org/10.1039/c3cp44299c

Faggian M, Sut S, Perissutti B, Baldan V, Grabnar I, Dall'Acqua S (2016) Natural deep eutectic solvents (NADES) as a tool for bioavailability improvement: pharmacokinetics of rutin dissolved in proline/glycine after oral administration in rats: possible application in nutraceuticals. Molecules, 21: E1531. https://doi.org/10.3390/molecules21111531

Florindo C, Celia-Silva LG, Martins LFG Branco LC, Marrucho IM (2018) Supramolecular hydrogel based on a sodium deep eutectic solvent. Chem Commun, 54: 7527-7530. https://doi.org/10.1039/c8cc03266a

Fourmentin S, Landy D, Cunha Gomes de Moura LM, Tilloy S, Bricout H, Ferreira M (2018) Procédé d'épuration d'un effluent gazeux. FR3058905.

Fu N, Li L, Liu K, Kim CK, Li J, Zhu T, Li J, Tang B (2019) A choline chloride-acrylic acid deep eutectic solvent polymer based on $\mathrm{Fe} 3 \mathrm{O} 4$ particles and $\mathrm{MoS} 2$ sheets (poly(ChCl-AA 
DES)@Fe3O4@MoS2) with specific recognition and good antibacterial properties for $\beta$ lactoglobulin in milk. Talanta, 197: 567-577. https://doi.org/10.1016/j.talanta.2019.01.072

Gállego I, Grover MA, Hud NV (2015) Folding and imaging of DNA nanostructures in anhydrous and hydrated deep-eutectic solvents. Angew Chem Int Ed Engl, 54: 6765-6769. https://doi.org/10.1002/anie.201412354

Gautam RK, Ahmed SA, Seth D (2018) Photophysics of thioflavin T in deep eutectic solvents. J Lumin, 198: 508-516. https://doi.org/10.1016/j.jlumin.2018.02.055

Gutiérrez A, Atilhan M, Aparicio S (2018) A theoretical study on lidocaine solubility in deep eutectic solvents. Phys Chem Chem Phys, 20: 27464-27473. https://doi.org/10.1039/c8cp05641b

Gutiérrez A, Aparicio S, Atilhan M (2019) Design of arginine-based therapeutic deep eutectic solvents as drug solubilization vehicles for active pharmaceutical ingredients. Phys Chem Chem Phys, 21: 10621-10634. https://doi.org/10.1039/c9cp01408j

Halder AK, Natalia M, Cordeiro DS (2019) Probing the environmental toxicity of deep eutectic solvents and their components: an in silico modeling approach. ACS Sustainable Chem Eng, 7: 10649-10660. https://doi.org/10.1021/acssuschemeng.9b01306

Haraźna K, Walas K, Urbańska P, Witko T, Snoch W, Siemek A, Jachimska B, Krzan M, Napruszewska BD, Witko M, Bednarz S, Guzik M (2019) Polyhydroxyalkanoate-derived hydrogen-bond donors for the synthesis of new deep eutectic solvents. Green Chem, 21: 3116-3126. https://doi.org/10.1039/C9GC00387H

Harifi-Mood AR, Ghobadi R, Divsalar A (2017) The effect of deep eutectic solvents on catalytic function and structure of bovine liver catalase. Int J Biol Macromol, 95: 115-120. https://doi.org/10.1016/j.ijbiomac.2016.11.043

Hattori T, Tagawa H, Inai M, Kan T, Kimura S, Itai S, Mitragotri S, Iwao Y (2019) Transdermal delivery of nobiletin using ionic liquids. Sci Rep, 9: 20191. https://doi.org/10.1038/s41598-019-56731-1

Hayyan M, Hashim MA, Hayyan A, Al-Saadi MA, AlNashef IM, Mirghani ME, Saheed OK (2013) Are deep eutectic solvents benign or toxic? Chemosphere, 90: 2193-2195. https://doi.org/10.1016/j.chemosphere.2012.11.004

Hayyan M, Looi CY, Hayyan A, Wong WF, Hashim MA (2015) In vitro and in vivo toxicity profiling of ammonium-based deep eutectic solvents. PLoS ONE, 10: e0117934. https://doi.org/10.1371/journal.pone.0117934 
Hayyan M, Mbous YP, Looi CY, Wong WF, Hayyan A, Salleh Z, Mohd-Ali O (2016) Natural deep eutectic solvents: cytotoxic profile. Springerplus, 5: 913. https://doi.org/10.1186/s40064-016-2575-9

Ibsen KN, Ma H, Banerjee A, Tanner EEL, Nangia S, Mitragotri S (2018) Mechanism of antibacterial activity of choline-based ionic liquids (CAGE). ACS Biomater Sci Eng, 4: 23702379. https://doi.org/10.1021/acsbiomaterials.8b00486

Jeliński T, Przybyłek M, Cysewski P (2019a) Solubility advantage of sulfanilamide and sulfacetamide in natural deep eutectic systems: experimental and theoretical investigations. Drug Dev Ind Pharm, 45: 1120-1129. https://doi.org/10.1080/03639045.2019.1597104

Jeliński T, Przybyłek M, Cysewski P (2019b) Natural deep eutectic solvents as agents for improving solubility, stability and delivery of curcumin. Pharm Res, 36: 116. https://doi.org/10.1007/s11095-019-2643-2

Juneidi I, Hayyan M, Mohd Ali O (2016) Toxicity profile of choline chloride-based deep eutectic solvents for fungi and Cyprinus carpio fish. Environ Sci Pollut Res Int, 23: 76487659. https://doi.org/10.1007/s11356-015-6003-4

Kellar R, Nieto NC, Koppisch A, Del Sesto R (2018) Ionic liquids that sterilize and prevent biofilm formation in skin wound healing devices. US20180093011.

Khodaverdian S, Dabirmanesh B, Heydari A, Dashtban-Moghadam E, Khajeh K, Ghazi F (2018) Activity, stability and structure of laccase in betaine based natural deep eutectic $\begin{array}{lllll}\text { solvents. } & \text { Int } & \mathrm{J} & \text { Biol } & \text { Macromol, }\end{array}$ https://doi.org/10.1016/j.ijbiomac.2017.10.144

Lee MS, Lee K, Nam MW, Jeong KM, Lee JE, Kim NW, Yin Y, Lim SY, Yoo DE, Lee J, Jeong JH (2018) Natural deep eutectic solvents as a storage medium for human interferon- $\alpha 2$ : a green and improved strategy for room-temperature biologics. J Ind Eng Chem, 65: 343-348. https://doi.org/10.1016/j.jiec.2018.05.005

Li Y, Wu X, Zhu Q, Chen Z, Lu Y, Qi J, Wu W (2019) Improving the hypoglycemic effect of insulin via the nasal administration of deep eutectic solvents. Int J Pharm, 569: 118584. https://doi.org/10.1016/j.ijpharm.2019.118584

Li Z, Lee PI (2016) Investigation on drug solubility enhancement using deep eutectic solvents and their derivatives. Int J Pharm, 505: 283-288. https://doi.org/10.1016/j.ijpharm.2016.04.018

Lim JH, Song SH, Park HS, Lee JR, Lee SM (2017) Spontaneous detachment of Streptococcus mutans biofilm by synergistic effect between zwitterion and sugar alcohol. Sci Rep, 7: 8107. https://doi.org/10.1038/s41598-017-08558-x 
Lim JH, Jeong Y, Song SH, Ahn JH, Lee JR, Lee SM (2018) Penetration of an antimicrobial zinc-sugar alcohol complex into Streptococcus mutans biofilms. Sci Rep, 8: 16154. https://doi.org/10.1038/s41598-018-34366-y

Lu C, Cao J, Wang N, Su E (2016) Significantly improving the solubility of non-steroidal anti-inflammatory drugs in deep eutectic solvents for potential non-aqueous liquid administration. Med Chem Commun, 7: 955-959. https://doi.org/10.1039/C5MD00551E

Macário IPE, Jesus F, Pereira JL, Ventura SPM, Gonçalves AMM, Coutinho JAP, Gonçalves FJM (2018a) Unraveling the ecotoxicity of deep eutectic solvents using the mixture toxicity theory. Chemosphere, 212: 890-897. https://doi.org/10.1016/j.chemosphere.2018.08.153

Macário IPE, Ventura SPM, Pereira JL, Gonçalves AMM, Coutinho JAP, Gonçalves FJM (2018b) The antagonist and synergist potential of cholinium-based deep eutectic solvents. Ecotoxicol Environ Saf, 165: 597-602. https://doi.org/10.1016/j.ecoenv.2018.09.027

Macário IPE, Oliveira H, Menezes AC, Ventura SPM, Pereira JL, Gonçalves AMM, Coutinho JAP, Gonçalves FJM (2019) Cytotoxicity profiling of deep eutectic solvents to human skin cells. Sci Rep, 9: 3932. https://doi.org.10.1038/s41598-019-39910-y

Mamashli F, Badraghi J, Delavari B, Lanjanian H, Sabbaghian M, Hosseini M, Saboury AA (2018) Improvement of versatile peroxidase activity and stability by a cholinium-based ionic liquid. J Mol Liq, 272: 597-608. https://doi.org/10.1016/j.molliq.2018.09.128

Mao S, Li K, Hou Y, Liu Y, Ji S, Qin H, Lu F (2018) Synergistic effects of components in deep eutectic solvents relieve toxicity and improve the performance of steroid biotransformation catalyzed by Arthrobacter simplex. J Chem Technol Biotechnol, 93: 27292736. https://doi.org/10.1002/jctb.5629

Mbous YP, Hayyan M, Wong WF, Looi CY, Hashim MA (2017) Unraveling the cytotoxicity and metabolic pathways of binary natural deep eutectic solvent systems. Sci Rep, 7: 41257. https://doi.org/10.1038/srep41257

McCune JA, Kunz S, Olesińska M, Scherman OA (2017) DESolution of CD and CB macrocycles. Chem Eur J, 23: 8601-8604. https://doi.org/10.1002/chem.201701275

Mitar A, Panić M, Prlić Kardum J, Halambek J, Sander A, Zagajski Kučan K, Radojčić Redovniković I, Radošević K (2019) Physicochemical properties, cytotoxicity, and antioxidative activity of natural deep eutectic solvents containing organic acid. Chem Biochem Eng Q, 33: 1-18. https://doi.org/10.15255/CABEQ.2018.1454

Mokhtarpour M, Shekaari H, Martinez F, Zafarani-Moattar MT (2019a) Study of naproxen in some aqueous solutions of choline-based deep eutectic solvents: Solubility measurements, 
volumetric and compressibility properties. Int J Pharm, 564: 197-206. https://doi.org/10.1016/j.ijpharm.2019.04.029

Mokhtarpour M, Shekaari H, Martinez F, Zafarani-Moattar MT (2019b) Effect of tetrabutylammonium bromide-dased deep eutectic solvents on the aqueous solubility of indomethacin at various temperatures: measurement, modeling, and prediction with threedimensional Hansen solubility parameters. AAPS PharmSciTech, 20: 204. https://doi.org/10.1208/s12249-019-1373-4

Morrison HG, Sun CC, Neervannan S (2009) Characterization of thermal behavior of deep eutectic solvents and their potential as drug solubilization vehicles. Int J Pharm, 378: 136-139. https://doi.org/10.1016/j.ijpharm.2009.05.039

Moufawad T, Moura L, Ferreira M, Bricout H, Tilloy S, Monflier E, Costa Gomes M, Landy D, Fourmentin S (2019) First evidence of cyclodextrin inclusion complexes in a deep eutectic solvent. ACS Sustainable Chem Eng, 7: 6345-6351. https://doi.org/10.1021/acssuschemeng.9b00044

Moura L, Moufawad T, Ferreira M, Bricout H, Tilloy S, Monflier E, Costa Gomes MF, Landy D, Fourmentin S (2017) Deep eutectic solvents as green absorbents of volatile organic pollutants. Environ Chem Lett, 15: 747-753. https://doi.org/10.1007/s10311-017-0654-y

Nascimento PAM, Picheli FP, Lopes AM, Pereira JFB, Santos-Ebinuma VC (2019) Effects of cholinium-based ionic liquids on Aspergillus niger lipase: Stabilizers or inhibitors. Biotechnol Prog, 35: e2838. https://doi.org/10.1002/btpr.2838

Niknaddaf F, Shahangian SS, Heydari A, Hosseinkhani S, Sajedi RH (2018) Deep eutectic solvents as a new generation of chemical chaperones. ChemistrySelect, 3: 10603-10607. https://doi.org/10.1002/slct.201802235

Nurunnabi M, Ibsen KN, Tanner EEL, Mitragotri S (2019) Oral ionic liquid for the treatment of diet-induced obesity. Proc Natl Acad Sci USA, 116: 25042-25047. https://doi.org/10.1073/pnas.1914426116

Olivares B, Martínez F, Rivas L, Calderón C, M Munita J, R Campodonico P (2018) A natural deep eutectic solvent formulated to stabilize $\beta$-lactam antibiotics. Sci Rep, 8: 14900. https://doi.org/10.1038/s41598-018-33148-w

Palmelund H, Andersson MP, Asgreen CJ, Boyd BJ, Rantanen J, Löbmann K (2019) Tailormade solvents for pharmaceutical use? Experimental and computational approach for determining solubility in deep eutectic solvents (DES). Int J Pharm: X, 1: 100034. https://doi.org/10.1016/j.ijpx.2019.100034 
Pedro SN, Freire MG, Freire CSR, Silvestre AJD (2019) Deep eutectic solvents comprising active pharmaceutical ingredients in the development of drug delivery systems. Expert Opin Drug Deliv, 16: 497-506. https://doi.org/10.1080/17425247.2019.1604680

Pereira CV, Silva JM, Rodrigues L, Reis RL, Paiva A, Duarte ARC, Matias A (2019) Unveil the anticancer potential of limomene based therapeutic deep eutectic solvents. Sci Re., 9: 14926. https://doi.org/10.1038/s41598-019-51472-7

Potticary J, Hall C, Hamilton V, McCabe JF, Hall SR (2019) Deep eutomic solvents. https://arxiv.org/abs/1902.08376v2

Pradeepkumar P, Rajendran NK, Alarfaj AA, Munusamy MA, Rajan M (2018) Deep eutectic solvent-mediated FA-g- $\beta$-Alanine-co-PCL drug carrier for sustainable and site-specific drug delivery. ACS Appl Bio Mater, 6: 2094-2109. https://doi.org/10.1021/acsabm.8b00554

Pradeepkumar P, Sangeetha R, Gunaseelan S, Varalakshmi P, A Chuturgoon A, Rajan M (2019a) Folic acid conjugated polyglutamic acid drug vehicle synthesis through deep eutectic solvent for targeted release of paclitaxel. ChemistrySelect, 4: 10225-10235. https://doi.org/10.1002/slct.201902256

Pradeepkumar P, Subbiah A, Rajan M (2019b) Synthesis of bio-degradable poly(2hydroxyethyl methacrylate) using natural deep eutectic solvents for sustainable cancer drug delivery. SN Applied Sciences, 1: 568. https://doi.org/10.1007/s42452-019-0591-4

Qi QM, Mitragotri S (2019) Mechanistic study of transdermal delivery of macromolecules assisted by ionic liquids. J Control Release, 311-312: 162-169. https://doi.org/10.1016/j.jconrel.2019.08.029

Qu W, Häkkinen R, Allen J, D’Agostino C, Abbott AP (2019) Globular and fibrous proteins modified with deep eutectic solvents: materials for drug delivery. Molecules, 24: 3583. https://doi.org/10.3390/molecules24193583

Radošević K, Bubalo MC, Srček VG, Grgas D, Dragičević TL, Redovniković IR (2015) Evaluation of toxicity and biodegradability of choline chloride based deep eutectic solvents. Ecotoxicol Environ Saf, 112: 46-53. https://doi.org/10.1016/j.ecoenv.2014.09.034

Radošević K, Ćurko N, Srček VG, Bubalo MC, Tomašević M, Ganić KK, Redovniković IR (2016) Natural deep eutectic solvents as beneficial extractants for enhancement of plant extracts bioactivity. LWT - Food Science and Technology, 73: 45-51. https://doi.org/10.1016/j.lwt.2016.05.037

Radošević K, Čanak I, Panić M, Markov K, Bubalo MC, Frece J, Srček VG, Redovniković IR (2018) Antimicrobial, cytotoxic and antioxidative evaluation of natural deep eutectic solvents. Environ Sci Pollut Res Int, 25: 14188-14196. https://doi.org/10.1007/s11356-018-1669-z 
Rogers RD, Gurau G (2018) Is “choline and geranate” an ionic liquid or deep eutectic solvent system? Proc Natl Acad Sci USA, 115: E10999. https://doi.org/10.1073/pnas.1814976115

Rozema E, van Dam AD, Sips HCM, Verpoorte R, Meijer OC, Kooijman S, Choi YH (2015) Extending pharmacological dose-response curves for salsalate with natural deep eutectic solvents. RSC Adv, 5: 61398-61401. https://doi.org/10.1039/C5RA10196D

Sadaf A, Kumari A, Khare SK (2018) Potential of ionic liquids for inhibiting the growth and $\beta$-lactamase production by Bacillus cereus EMB20. Int J Biol Macromol, 107: 1915-1921. https://doi.org/10.1016/j.ijbiomac.2017.10.053

Sanchez-Fernandez A, Edler KJ, Arnold T, Alba Venero D, Jackson AJ (2017) Protein conformation in pure and hydrated deep eutectic solvents. Phys Chem Chem Phys, 19: 86678670. https://doi.org/10.1039/c7cp00459a

Santos F, Leitão MIPS, Duarte ARC (2019) Properties of therapeutic deep eutectic solvents of L-arginine and ethambutol for tuberculosis treatment. Molecules, 24: 55. https://doi.org/10.3390/molecules24010055

Santos de Almeida T, Júlio A, Saraiva N, Fernandes AS, Araújo MEM, Baby AR, Rosado C, Mota JP (2017) Choline- versus imidazole-based ionic liquids as functional ingredients in topical delivery systems: cytotoxicity, solubility, and skin permeation studies. Drug Dev Ind Pharm, 43: 1858-1865. https://doi.org/10.1080/03639045.2017.1349788

Scherman OA, McCune JA (2018) Deep eutectic solvent compositions. WO2018167315.

Shamseddin A, Crauste C, Durand E, Villeneuve P, Dubois G, Durand T, Vercauteren J, Veas F (2017) Resveratrol formulated with a natural deep eutectic solvent inhibits active matrix metalloprotease-9 in hormetic conditions. Eur J Lipid Sci Technol, 119: 1700171. https://doi.org/10.1002/ejlt.201700171

Shekaari H, Zafarani-Moattar MT, Mokhtarpour M (2017) Solubility, volumetric and compressibility properties of acetaminophen in some aqueous solutions of choline based deep eutectic solvents at $\mathrm{T}=(288.15$ to 318.15$)$ K. Eur $\mathrm{J}$ Pharm Sci, 109: 121-130. https://doi.org/10.1016/j.ejps.2017.07.021

Shekaari H, Zafarani-Moattar MT, Mokhtarpour M (2018a) Experimental determination and correlation of acetaminophen solubility in aqueous solutions of choline chloride based deep eutectic solvents at various temperatures. Fluid Phase Equilib, 462: 100-110. https://doi.org/10.1016/j.fluid.2018.01.017

Shekaari H, Zafarani-Moattar MT, Shayanfar A, Mokhtarpour M (2018b) Effect of choline chloride/ethylene glycol or glycerol as deep eutectic solvents on the solubility and 
thermodynamic properties of acetaminophen. J Mol Liq, 249: 1222-1235. https://doi.org/10.1016/j.molliq.2017.11.057

Shekaari H, Zafarani-Moattar MT, Mokhtarpour M, Faraji S (2019) Exploring cytotoxicity of some choline-based deep eutectic solvents and their effect on the solubility of lamotrigine in aqueous media. J Mol Liq, 283: 834-842. https://doi.org/10.1016/j.molliq.2019.03.079

Sidat Z, Marimuthu T, Kumar P, du Toit LC, Kondiah PPD, Choonara YE, Pillay V (2019) Ionic liquids as potential and synergistic permeation enhancers for transdermal drug delivery. Pharmaceutics, 11: 96. https://doi.org/10.3390/pharmaceutics11020096

Silva NHCS, Pinto RJB, Martins MA, Ferreira R, Correia I, Freire CSR, Marrucho IM (2018a) Ionic liquids as promoters of fast lysozyme fibrillation. J Mol Liq, 272: 456-467. https://doi.org/10.1016/j.molliq.2018.08.064

Silva NHCS, Vilela C, Pinto RJB, Martins MA, Marrucho IM, Freire CSR (2018b) Tuning lysozyme nanofibers dimensions using deep eutectic solvents for improved reinforcement ability. Int J Biol Macromol, 115: 518-527. https://doi.org/10.1016/j.ijbiomac.2018.03.150

Silva JM, Silva E, Reis RL, Duarte ARC (2019) A closer look in the antimicrobial properties of deep eutectic solvents based on fatty acids. Sustain Chem Pharm, 14: 100192. https://doi.org/10.1016/j.scp.2019.100192

Sivapragasam M, Wilfred CD, Jaganathan JR, Krishnan S, Ghani WAWAK (2019) Cholinebased ionic liquids as media for the growth of Saccharomyces cerevisiae. Processes, 7: 471. https://doi.org/10.3390/pr7070471

Stott PW, Williams AC, Barry BW (1998) Transdermal delivery from eutectic systems: enhanced permeation of a model drug, ibuprofen. J Control Release, 50: 297-308. https://doi.org/10.1016/S0168-3659(97)00153-3

Su E, Klibanov AM (2015) Low-transition-temperature mixtures (LTTMs) for dissolving proteins and for drug formulation. Appl Biochem Biotechnol, 177: 753-758. https://doi.org/10.1007/s12010-015-1777-X

Sut S, Faggian M, Baldan V, Poloniato G, Castagliuolo I, Grabnar I, Perissutti B, Brun P, Maggi F, Voinovich D, Peron G, Dall'Acqua S (2017) Natural deep eutectic solvents (NADES) to enhance Berberine absorption: an in vivo pharmacokinetic study. Molecules, 22: E1921. https://doi.org/10.3390/molecules22111921

Tang N, Zhong J, Yan W (2016) Solubilities of Three Flavonoids in Different Natural Deep Eutectic Solvents at $\mathrm{T}=(288.15$ to 328.15$) \mathrm{K}$. J Chem Eng Data, 61: 4203-4208. https://doi.org/10.1021/acs.jced.6b00552 
Tanner EEL, Ibsen KN, Mitragotri S (2018) Transdermal insulin delivery using choline-based ionic liquids (CAGE). J Control Release, 286: 137-144. https://doi.org/10.1016/j.jconrel.2018.07.029

Tanner EEL, Curreri AM, Balkaran JP1, Selig-Wober NC, Yang AB, Kendig C, Fluhr MP, Kim N, Mitragotri S (2019) Design principles of ionic liquids for transdermal drug delivery. Adv Mater, 31: e1901103. https://doi.org/10.1002/adma.201901103

Tarate B, Bansal AK (2015) Characterization of CoQ 10-lauric acid eutectic system. Thermochim Acta, 605: 100-106. https://doi.org/10.1016/j.tca.2015.01.018

Tateishi-Karimata H, Sugimoto N (2014) Structure, stability and behaviour of nucleic acids in ionic liquids. Nucleic Acids Res, 42: 8831-8844. https://doi.org/10.1093/nar/gku499

Tønnesen HH, Wikene KO (2016) Eutectic solvents and uses thereof. WO2016108083.

Torregrosa-Crespo J, Marset X, Guillena G, Ramón DJ, María Martínez-Espinosa R (2020) New guidelines for testing "Deep eutectic solvents" toxicity and their effects on the environment and living beings. Sci Total Environ, 704: 135382. https://doi.org/10.1016/j.scitotenv.2019.135382

Vanda H, Dai Y, Wilson EG, Verpoorte R, Choi YH (2018) Green solvents from ionic liquids and deep eutectic solvents to natural deep eutectic solvents. C.R. Chimie, 21: 628-638. https://doi.org/10.1016/j.crci.2018.04.002

Wang J, Dong X, Yu Q, Baker SN, Li H, Larm NE, Baker GA, Chen L, Tan J, Chen M (2017) Incorporation of antibacterial agent derived deep eutectic solvent into an active dental composite. Dent Mater, 33: 1445-1455. https://doi.org/10.1016/j.dental.2017.09.014

Wen Q, Chen JX, Tang YL, Wang J, Yang Z (2015) Assessing the toxicity and biodegradability of deep eutectic solvents. Chemosphere, 132: 63-69. https://doi.org/10.1016/j.chemosphere.2015.02.061

Wikene KO, Bruzell E, Tønnesen HH (2015a) Characterization and antimicrobial phototoxicity of curcumin dissolved in natural deep eutectic solvents. Eur J Pharm Sci, 80: 26-32. https://doi.org/10.1016/j.ejps.2015.09.013

Wikene KO, Bruzell E, Tønnesen HH (2015b) Improved antibacterial phototoxicity of a neutral porphyrin in natural deep eutectic solvents. J Photochem Photobiol B, 148: 188-196. https://doi.org/10.1016/j.jphotobiol.2015.04.022

Wikene KO, Rukke HV, Bruzell E, Tønnesen HH (2016) Physicochemical characterisation and antimicrobial phototoxicity of an anionic porphyrin in natural deep eutectic solvents. Eur J Pharm Biopharm, 105: 75-84. https://doi.org/10.1016/j.ejpb.2016.06.001 
Wikene KO, Rukke HV, Bruzell E, Tønnesen HH (2017) Investigation of the antimicrobial effect of natural deep eutectic solvents (NADES) as solvents in antimicrobial photodynamic $\begin{array}{lllll}\text { therapy. } & \text { P Photochem } & \text { Photobiol }\end{array}$ https://doi.org/10.1016/j.jphotobiol.2017.04.030

Wojnarowska Z, Smolka W, Zotova J, Knapik-Kowalczuk J, Sherif A, Tajber L, Paluch M (2018) The effect of electrostatic interactions on the formation of pharmaceutical eutectics. Phys Chem Chem Phys, 20: 27361-27367. https://doi.org/10.1039/c8cp05905e

Wolbert F, Brandenbusch C, Sadowski G (2019) Selecting excipients forming therapeutic deep eutectic systems - a mechanistic approach. Mol Pharm, 16: 3091-3099. https://doi.org/10.1021/acs.molpharmaceut.9b00336

Zakrewsky M, Lovejoy KS, Kern TL, Miller TE, Le V, Nagy A, Goumas AM, Iyer RS, Del Sesto RE, Koppisch AT, Fox DT, Mitragotri S (2014) Ionic liquids as a class of materials for transdermal delivery and pathogen neutralization. Proc Natl Acad Sci USA, 111: 1331313318. https://doi.org/10.1073/pnas.1403995111

Zakrewsky M, Mitragotri S, Fox DT, Koppisch A, Del Sesto R, Lovejoy K (2015) Ionic liquids for transdermal drug delivery. WO2015066647.

Zakrewsky M, Banerjee A, Apte S, Kern TL, Jones MR, Sesto RE, Koppisch AT, Fox DT, Mitragotri S (2016b) Choline and geranate deep eutectic solvent as a broad-spectrum antiseptic agent for preventive and therapeutic applications. Adv Healthc Mater, 5: 12821289. https://doi.org/10.1002/adhm.201600086

Zakrewsky M, Mitragotri S, Fox DT, Koppisch A, Del Sesto R, Lovejoy K (2016b) Ionic liquids for transdermal drug delivery. US20160263225.

Zhang Y, Du C, Cong Y, Xue Y, Qiao B, Ye T, Wang M (2019) Solubility increment and thermodynamic analysis of bioactive antofloxacin hydrochloride in aqueous $\mathrm{ChCl/PTS}$ deep eutectic solvent and cosolvent mixtures. J Chem Eng Data, 64: 5748-5754. https://doi.org/10.1021/acs.jced.9b00717 